\title{
ESTUDIO DEL HOLOCAUSTO DESDE LA VISIÓN DEL DERECHO INTERNACIONAL HUMANITARIO Y DERECHO PENAL INTERNACIONAL CONTEMPORÁNEO ${ }^{1}$
}

\section{RESUMEN:}

\author{
Rafael Andree Salgado Mejía²
}

El filósofo y psiquiatra alemán, Karl Jaspers, expresó sobre el Holocausto: "Lo que ha sucedido es un aviso. Olvidarlo es un delito. Fue posible que eso sucediera y sigue siendo posible que en cualquier momento vuelva a suceder." Ésta sentencia no se aleja de la realidad ya que, a la postre se materializaron diversas situaciones violencia generalizada ${ }^{3}$ como ser las ocurridas durante la desintegración de la ex Yugoslavia (masacre de Srebrenica, Bosnia-Herzegovina); las sucedidas en Ruanda, en dónde la población civil Hutu, tras años de adoctrinamiento gubernamental anti Tutsi, se dio a la tarea de exterminar a estos; las acontecidas en Camboya durante el periodo de gobierno del Partido Comunista de Kampuchea, conocido como el Khmer Rouge o Jemer Rojo; las acaecidas en Guatemala en perjuicio de la población indígena Maya, entre otras.

De aquí se desprende la necesidad del estudio de estas situaciones de violencia generalizada. Para efectos del presente artículo de investigación, se ha seleccionado El Holocausto, para desarrollar en su contexto, los tipos penales que se encuentran en el Estatuto de Roma de la Corte Penal Internacional, a excepción del Crimen de Agresión debido a que aún no se ha acordado su definición.

Asimismo, se analizará el proceso de surgimiento de un Genocidio, a través de las diez etapas de Gregory H. Stanton; se estudiaran las herramientas nacionales e internacionales de prevención que se utilizaron durante y después del conflicto, y los juicios nacionales e internacionales que se llevaron a cabo para imputar responsabilidad penal a los perpetradores, con el objetivo de que el lector pueda identificar y analizar los diversos elementos que se irán desarrollando y aplicarlos de forma práctica a una situación real y actual de violencia generalizada, o, a otras equiparables y ocurridas en el pasado como las antes mencionadas, es decir, si bien este artículo se enfoca en El Holocausto, el propósito real del mismo es brindar los instrumentos necesarias para estudiar situaciones de violencia generalizada para identificar sus etapas de surgimiento y así tomar las medidas idóneas que debiesen optarse para evitar las mismas o bien, enfrentarlas.

PALABRAS CLAVE: Responsabilidad de Proteger, Justicia Transicional, Corte Penal Internacional, tribunal de Núremberg, Holocausto, Genocidio, Lesa Humanidad Crimen de Guerra.

Recibido: 04 de enero 2018

Aprobado: 07 de marzo 2018

\footnotetext{
1 Se le agradece a la Fundación Museo de la Memoria y los Derechos Humanos de Santiago de Chile, Chile por haber permitido realizar una estancia de Investigación presencial y no presencial en el área de Educación y Audiencias desde el 4 de Julio de 2017 hasta el 28 de Julio de 2017 . Aclarándose que, dicha institución sólo prestó servicios como centro de documentación por lo que lo expresado en el presente artículo es de mi exclusiva responsabilidad. 2 Abogado por la Universidad Nacional Autónoma de Honduras (UNAH) y actualmente pasante universitario en la Maestría en Derechos Humanos por la Universidad Iberoamericana, México. Becario de maestría por la Agencia Mexicana de Cooperación Internacional para el Desarrollo (AMEXCID). rasmsr@hotmail.com

3 El Alto Comisionado de las Naciones Unidas para los Refugiados (ACNUR) ha interpretado la violencia generalizada de la siguiente manera: La "violencia generalizada" no es un término técnico, ni tampoco tiene una definición estricta o cerrada. Al adoptar un enfoque de análisis de caso individual, el término incluiría situaciones caracterizadas por una violencia tan indiscriminada y generalizada al punto de afectar a grandes grupos de personas o a poblaciones enteras obligándolas a huir. Las situaciones de violencia generalizada claramente incluirían situaciones que impliquen violaciones masivas y graves de los derechos humanos. Sin embargo, no siempre es la intensidad de la violencia lo que la haría generalizada, sino más bien su extensión y densidad geográfica. Las situaciones de violencia generalizada incluirían la violencia ejercida por el Estado, así como por actores no estatales, en este último caso, cuando la voluntad o la capacidad del Estado para brindar protección a quienes están bajo su jurisdicción son inadecuadas. Dicho esto, el punto de discusión es la situación sobre el terreno y el riesgo que tal violencia representa -en lugar de la cuestión de la responsabilidad del Estado. Los efectos de este tipo de violencia también podrían ser una consideración relevante, incluso si la violencia se prolonga en el tiempo y/o el espacio. (ACNUR, 2013, párrs. 15-18)
} 


\title{
STUDY OF THE HOLOCAUST FROM DE VISION OF INTERNATIONAL HUMANITARIAM LAW AND CONTEMPORARY INTERNATIONAL CRIMINAL LAW
}

\author{
Rafael Andree Salgado Mejía*
}

\begin{abstract}
:
The German philosopher and psychiatrist, Karl Jaspers, reported on the Holocaust: "What has happened is a warning. Forgetting it is a crime. It was possible that this happened and it is still possible that a successor will be produced at any moment. "This is a sentence that is not known more than the reality that has occurred in the disintegration of the former Yugoslavia (Massacre of Srebrenica, Bosnia-Herzegovina ), the events in Rwanda, where the Hutu civilian population is, after years of anti-Tutsi government indoctrination, were given the task of exterminating these, those that occurred in Cambodia during the period of government of the Communist Party of Kampuchea, known as the Khmer Rouge; the victims in Guatemala to the detriment of the Mayan indigenous population, among others.
\end{abstract}

Hence the need to study these situations of violence generalization. For the purposes of this research article, the Holocaust has been selected, to develop in its context; the criminal types found in the Rome Statute of the International Criminal Court, with the exception of the Crime of Aggression Due that its definition has not yet been agreed.

Also, the process of the emergence of a genocide will be analyzed, through the ten stages of Gregory $\mathrm{H}$. Stanton; the national and international tools of prevention that are used during and after the conflict will be studied, and the national and international judgments that it is a matter to impute the criminal responsibility of the perpetrators, with the objective that the reader can identify and analyze the various elements that will be developed and applied in a practical way to a real and current situation of generalized violence, or, to other comparable and occurred in the past as the aforementioned, that is, although this article focuses on the Holocaust, the purpose real is to provide the necessary tools to study situations of generalized violence to identify their stages of emergence and thus take the appropriate measures that should be chosen to avoid it or face them.

KEYWORDS: Responsibility to Protect, Transitional Justice, International Criminal Court, Nuremberg Tribunal, Holocaust, Genocide, Crime against humanity, War Crime.

Received: January 4, 2018

Approved: March 7, 2018

1. Thank you to the Foundation Museum of Memory and Human Rights of Santiago, Chile, for having allowed a stay of In-person and non-face-to-face research in the area of Education and Hearing from July 4, 2017 to July 28. July 2017. Clarifying that the said institution only provided services as a documentation center, so that what is expressed in this article is my sole responsibility.

2. Lawyer from the National Autonomous University of Honduras (UNAH) and currently a university intern in the Master's Degree in Human Rights from the Universidad Iberoamericana, Mexico. Master's fellow by the Mexican Agency for International Development Cooperation (AMEXCID).rasmsr@hotmail.com 


\section{INTRODUCCIÓN}

Se estudiará una situación de violencia generalizada para identificar sus etapas de surgimiento y así identificar cuáles son las medidas indicadas para evitarlas 0 enfrentarlas. Esto permitirá que, se puedan estudiar otras situaciones de violencia generalizada haciendo uso de una metodología similar a la del presente artículo, es decir, que sina de referencia para el estudio de situaciones de violencia generalizada. Es por ello que se ha elegido un caso específico para que su estudio vaya en armonía con cada uno de los elementos que se irán desarrollando: El Holocausto.

El Holocausto es una de las atrocidades mejores documentadas en la historia y significó para la humanidad un retroceso en la consolidación y protección de los derechos humanos, por tal motivo, se abordará desde una visión del Derecho Internacional Humanitario y del Derecho Penal Internacional contemporáneos.

Para iniciar en el desarrollo del presente artículo, es importante definir el término de Holocausto, que procede del griego "holokáustos" que significa "completamente quemado", el cual hace referencia a una antigua práctica religiosa generalizada de la quema de los animales como víctimas ${ }^{4}$. Dicha expresión comienza a ser utilizado a partir del genocidio $^{5}$ ocurrido durante la Segunda Guerra Mundial (en adelante: II GM). No obstante, el término "genocidio" fue propuesta hasta el año 1944 en la obra del polaco-judío Rafaël Lemkin titulada: Axis Rule in Occupied Europe: Laws of Occupation. Analysis of Government, Proposals for Redress ${ }^{6}$ (Tinajero \& Guevara, ¿Qué es el genocidio?, 4 "...Das griechische Wort holókaustos ("vollständig verbrannt") bezog sich auf die in der Antike verbreitete religiöse Praxis der Verbrennung von Tieren als Opfer"(Traducción propia), (Antisemitismus.net)

5 "La palabra genocidio, como la mayor parte de los doctrinarios nos lo recuerdan, es el producto de la suma de dos raíces grecolatinas: genos, que en griego significa raza o tribu; y cidio, que en latín significa muerte o matar" (Tinajero \& Guevara, ¿Qué es el genocidio?, 2013, pág. 18)

6 Reglas del Eje en la Europa Ocupada: Leyes de la Ocupación.
2013 , pág. 17 y 18), y la definición aparece en un instrumento internacional hasta el 9 de diciembre de $1948^{7}$. Cuando se utiliza con nombre propio, El Holocausto se refiere a la persecución y el asesinato masivo y sistemático de aproximadamente seis millones de judíos e igualmente de gitanos, eslavos, personas discapacitadas, homosexuales y testigos de Jehová por la Alemania nazi y sus colaboradores, quienes entre 1933 y 1945, también encarcelaron y aniquilaron por razones políticas a comunistas y prisioneros de guerra soviéticos. (Museo Memoria y Tolerancia, 2013, pág. 5).

\section{METODOLOGÍA}

En primer lugar se estudiará el proceso de surgimiento del conflicto bajo las diez etapas de Gregory H. Stanton, lo que permite que se puedan tomar medidas de forma anticipada, previo a la cristalización del mismo. Luego, se estudiaran los juicios nacionales e internacionales que se llevaron a cabo para imputar responsabilidad penal a los perpetradores, con énfasis en los juicios de Núremberg y se explicará, para ilustrar al lector, por qué no fue aplicable la competencia de la Corte Penal Internacional (En adelante CPI) al presente caso. Los anteriores aspectos permitirán introducirnos en el tema de las herramientas nacionales e internacionales de prevención que se utilizaron durante y después del conflicto, concluyendo con la identificación de los crímenes internacionales tipificados en el Estatuto de Roma (En adelante ER) de la CPI es decir, Crimen de Guerra, Lesa Humanidad y Genocidio, a excepción del crimen de Agresión por los motivos explicados en líneas anteriores.

\section{ETAPAS DEL SURGIMIENTO DEL CONFLICTO}

El Dr. Gregory H. Stanton (2013) indica que el genocidio es un proceso que se desarrolla en diez etapas que son predecibles pero no inexorables

Análisis del Gobierno, Propuestas de Resarcimiento (Traducción propia)

7 Convención para la prevención y la sanción del delito de genocidio, 1948, Artículo II. 
las cuales son las siguientes: 1) Clasificación, 2) Simbolización, 3) Discriminación, 4) Deshumanización, 5) Organización, 6) Polarización, 7) Preparación, 8) Persecución, 9) Exterminación, y; 10) Negación. Asimismo, indica que estas etapas no se cristalizan de forma lineal, sino que, podrían ocurrir simultáneamente pero todas las etapas continuaran operando a lo largo del proceso. En este apartado identificaremos las referidas etapas en el que el Holocausto se fue desarrollando.

La clasificación, es decir, la distinción de las personas en "nosotros y ellos" más notable en este caso era entre alemanes y judíos: los judíos vivían en todos los países de Europa y aproximadamente nueve millones de judíos vivían en los países que serían ocupados por Alemania durante la II GM (United States Holocaust Memorial Museum). La comunidad judía más grande en la Europa Central, antes de la II GM, estaba en Alemania con alrededor de 525.000 miembros, seguía Hungría con 445.000, Checoslovaquia con 357.000, y Austria con 250.000 (United States Holocaust Memorial Museum). Estos tenían más de dos mil años viviendo en Europa llevando una vida ordinaria y participaban desde diversos ámbitos en la trasformación y desarrollo del continente (Museo Memoria y Tolerancia, Ciudad de México, 2011., pág. 14).

Es identificable la cristalización de la clasificación por parte de Adolf Hitler cuando empieza a escribir en prisión ${ }^{8}$ "Mein Kampf" (Mi Lucha) en donde plantea las tesis principales del "peligro judío" y describe su antipatía al comunismo y el judaísmo. En relación a esta etapa, en su capítulo II: "Wiener Lehr-und Leidensjahre" (Enseñanza Vienés y años de sufrimiento ${ }^{9}$ ), es identificable la cristalización de

8 En 1923 Adolf Hitler en medio de una gran polarización política, intentó dar un golpe de Estado desde Múnich con apoyo de un sector del ejercito, pero fracaso en su intento y fue arrestado (Museo Memoria y Tolerancia, 2013).

9 La traducción es propia. En la edición electrónica de "Mein Kampf": Adolf Hitler. Mi Lucha. Primera Edición electrónica, 2003.Jusego-Chile.disponible en: http://der-stuermer.org/ spanish/Adolf\%20Hitler-Mi\%20Lucha.pdf; lo titulan como: "Las experiencias de mi vida en Viena”. esta etapa cuando él empieza a reflexionar sobre las ocasiones en que en algunos lugares de la ciudad se encontraba con transeúntes de ciertos rasgos físicos que le llamaban poderosamente la atención y trataba de identificar si se trataban de judíos o alemanas, preguntándose a sí mismo: ¿Será un judío?, y luego replanteándose: ¿Será también éste un alemán? ${ }^{10}$.

Otra distinción identificada en esta etapa seria entre los alemanes y gitanos ${ }^{11}$. Propiamente al hecho de clasificar a estos grupos de personas y nombrarlas como "gitanos" o "judíos" se podría decir que hubo una simbolización que progresivamente se fue deshumanizando en mayor medida al grado que a los judíos con fines segregacionistas y discriminatorios, obligaban a portar una estrella de David sobre un fondo amarillo con la palabra en alemán "Jude" o solo una "J", y; se les asignaba un nuevo segundo nombre para todos los judíos que no tuvieran nombres que los identificaran como tales: "Israel" para los varones y "Sara" para las mujeres (United States Holocaust Memorial Museum). Pero para llegar a esta deshumanización es necesario retroceder unos años antes previos a la II GM para

10 Cierta vez, al caminar por los barrios del centro, me vi de súbito frente a un hombre de largo chaflán y de rizos negros. ¿Será un judío?, fue mi primer pensamiento. Los judíos de Linz no tenían ciertamente esa apariencia racial. Observé al hombre sigilosamente, $y$, a medida que me fijaba en su extraña fisonomía, rasgo por rasgo, fue transformándose en mi mente la primera pregunta en otra inmediata: ¿Será también éste un alemán? (Hitler, 2003, págs. 37 38) La cuestión me parecía tan trascendental y las acusaciones de tal magnitud que, torturado por el temor de ser injusto, me sentía vacilante e inseguro. Naturalmente que ya no era dable dudar de que no se trataba de alemanes de una creencia religiosa especial, sino de un pueblo diferente en sí; pues desde que me empezó a preocupar la cuestión judía, cambió mi primera impresión sobre Viena. Por doquier veía judíos, y, cuanto más los observaba, más se diferenciaban a mis ojos de las demás gentes. (Hitler, 2003, pág. 38)

11 Los gitanos, desde su llegada a Europa Central en el siglo XV habían sido socialmente excluidos. Este grupo social se conformaba por diferentes "tribus" o "naciones; se consideraba una minoría étnica que recibió el nombre de gitanos, porque se creía que tenían orígenes gitanos. Las tribus Sinti y Roma (gitanos) eran las más comunes en Alemania y Austria respectivamente; ambas tribus fueron calificadas de "inferiores" racialmente (Museo Memoria y Tolerancia, 2013, pág. 14). 
explicar mejor este proceso.

Al momento en que Alemania firma el Tratado de Versalles en 1919, mismo que lo sometía a severas restricciones territoriales, militares y económicas, se instauró un nuevo régimen: La República de Weimar, régimen que no era de la confianza del pueblo Alemán, lo que le permitió crecer a grupos políticos como al Partido Comunista Alemán y Partido Nacional Socialista Obrero Alemán (United States Holocaust Memorial Museum). Hitler teniendo una buena lectura de estas situaciones les prometió a los desencantados una mejor vida y una nueva y gloriosa Alemania, su partido apelaba especialmente a los desempleados, los jóvenes y a las personas de la clase media baja, lo que permitió que en las elecciones de 1932 los nazis ganaran el 33 por ciento de los votos, más que cualquier otro partido (United States Holocaust Memorial Museum).

El 30 de enero de 1933, el presidente alemán Paul Von Hindenburg nombra a Hitler como canciller y el 2 de agosto de 1934 tras la muerte de quien lo había nombrado, Hitler se proclama líder único en Alemania convirtiéndose en dictador absoluto. Las ideologías del Partido Nazi eran una combinación de propuestas radicales del fascismo, racismo, antisemitismo y el darwinismo social, e incluso utilizaron teorías seudocientíficas para demostrar la primacía de ciertas razas sobre otras y evitar que la raza aria perdiera su "pureza" al combinarse con otras consideradas inferiores como los gitanos, negros y los judíos (Museo Memoria y Tolerancia, Ciudad de México, 2011., págs. 12-13). Todo lo anteriormente mencionado conllevó que desde los primeros años del partido nazi en el poder se materializara la etapa de la discriminación porque se promulgaron leyes ${ }^{12}$ que restringían los derechos civiles, políticos y económicos de los judíos, como el ejercer profesiones, estudiar en universidades,

12 Luego de haber sido abolidos los derechos fundamentales de la Constitución de Weimar mediante el estatuto de emergencia "para la protección del pueblo y el Estado", fue ampliamente dejada de lado la división de poderes mediante la Ley de Otorgamiento de Poderes (Ermächtigungsgesetz), de modo que incluso las leyes para una reforma constitucional podían ser sancionadas por el propio gobierno. (Ambos \& Meyer, 2009, pág. 436) utilizar espacios públicos o pertenecer a ciertas organizaciones (Museo Memoria y Tolerancia, Ciudad de México, 2011., pág. 14).

Las leyes de raciales de Núremberg ${ }^{13}$ de 1935 negaban a los judíos la ciudadanía alemana y les prohibían casarse o tener relaciones sexuales con personas de "sangre alemana o afín"; igualmente, en 1935 se califica como delito todo acto homosexual; en 1933 se iniciaron los boicots nazis a los comercios judíos a nivel nacional; asimismo, se consideró como "degenerados" determinados tipos de música, libros y pinturas, denominándolas: Entartete Kunst (arte degenerado) por diferentes motivos; en general, porque se oponían a los fundamentos del régimen en virtud de su contenido o la filiación política o racial de sus autores, por ello el 10 de mayo de 1933 se realizó la quema de libros en Alemania.

Entre el 9 y 10 de diciembre de 1938 en toda Alemania y territorios anexados de Austria y Checoslovaquia durante la noche se produjeron violentas persecuciones en las cuales murieron cerca de cien judíos, más de treinta mil fueron arrestados, se destruyeron alrededor de 7,500 comercios y más de 250 sinagogas con la aquiescencia del Estado (Museo Memoria y Tolerancia, Ciudad de México, 2011., pág. 16) ya que la policía no hizo nada para impedirlo y los bomberos tenía órdenes de no apagar los incendios, a estos eventos se le llamó "Die Kristallnacht"14. Las anteriores circunstancias fortalecieron el pogromo ${ }^{15}$ denominado la "arianización", es decir, la transferencia de comercios de propiedad judía a los "arios", se aceleró (United States Holocaust Memorial Museum).

13 Nürnberger Rasse-Gesetze: La Ley de Ciudadanía del Reich y La Ley para la Protección de la Sangre y el Honor Alemanes.

14 Al castellano es traducido como: "La noche de los cristales" o "la noche de los cristales rotos". Aunque los funcionarios del partido nazi describieron este hecho como un acto espontáneo de indignación pública, en respuesta al asesinato de un diplomático alemán por parte de un joven judío en París, se dice que la participación de la población fue limitada (United States Holocaust Memorial Museum).

15 Masacre, aceptada o promovida por el poder, de judíos y, por ext., de otros grupos étnicos (Real Academia Española, 2017). 
Estos actos discriminatorios coinciden con la etapa de la deshumanización porque según las teorías raciales los problemas que aquejaban a la nación eran por causa de las "razas inferiores" y para impedir la "contaminación" de la raza aria se debía eliminar a los judíos por ser catalogada como infrahumana, también a los gitanos por ser inferiores, las personas con alguna discapacidad por ser una carga; a los homosexuales por ser corruptores de sangre, a los testigos de Jehová por no subyugarse y a los intelectuales por deformar la mente (Museo Memoria y Tolerancia, 2013, pág. 6). Es importante mencionar que en principio las Políticas nazis estaban orientadas a expulsar a los judíos así como a las razas consideradas inferiores de Alemania y territorios anexados a través de la exclusión y violencia. Sin embargo, al irse deshumanizando el conflicto se empieza a tornar más violento los actos en contra de estos grupos. En cuanto a la organización el régimen contaba con una amplia gama de estructuras para efectuar sus objetivos los cuales mencionaré algunos:

I. Una policía secreta denominada "La Gestapo", término que es un acrónimo que deriva de la Geheimstaatspolizei, o Policía Estatal Secreta que junto con el Sicherheitsdienst (SDServicio de Seguridad), Kriminalpolizei (KripoPolicía Judicial o criminal), y la Ordnungspolizei (Orpo-Orden Policial), formó parte importante de la extensa organización de la policía nazi. Como tal, fue un componente vital tanto en la represión nazi como en el Holocausto y era responsable de combatir el contraespionaje y las acciones criminales contra el Estado y el Partido Nazi. Esta fuerza policial era diferente a otras en que no respondía a ninguna supervisión judicial o legal. Podría llevar a cabo acciones particularmente despiadadas sin temor a ninguna repercusión civil (United States Holocaust Memorial Museum).

II. Adolf Hitler para mantener el orden y el control en los mítines y asambleas, entre 1920 y 1921 ordena se establezca una especie de escuadrón o batallón paramilitar de veteranos de guerra uniformados con camisas de color pardo, la "División Tormenta" o "SturmAbteilung (SA)", sin embargo eran llamados los "camisas pardas" y su misión consistía en expulsar de los mítines a aquellas personas que demostraban su disconformidad o alteraban el orden (Historia virtual del Holocausto). Estos eran conocidos por su brutalidad y la violencia y eran potentes instrumentos de la calle de terror durante el ascenso de Hitler al poder. Empero, Los líderes de estas tropas de asalto en 1934 fueron purgadas por conductas embarazosas e intrigas políticas y se mantendría la SA, pero como una división dependiente de la fuerza política (United States Holocaust Memorial Museum).

III. "Die Schutzstaffel" (SS) o "Escuadrones de Protección". Estaban formados por hombres que se percibían como la "élite racial" del futuro nazi. En el estado nazi asumieron la responsabilidad principal de la seguridad, la identificación de la etnicidad, el establecimiento y la política de la población, y la colección y el análisis de la inteligencia. También controlaban las fuerzas de policía alemanas, el sistema de campos de concentración y concibieron e implementaron planes para reestructurar la composición étnica de Europa del Este y la Unión Soviética ocupada. A partir de 1939 asumieron la responsabilidad de "resolver" la llamada Cuestión Judía; Después de 1941, su dirección planificó, coordinó y dirigió la así llamada "Solución Final" (United States Holocaust Memorial Museum).

IV. Die Einsatzgruppen (Unidades móviles de matanza) Eran escuadras compuestas principalmente por personal de la SS y de la policía. Bajo el mando de los oficiales de la Policía de Seguridad de Alemania (Sicherheitspolizei: Sipo) y del SD. Su misión 
era asesinar a los enemigos considerados raciales o políticos encontrados detrás de líneas de combate alemanas en la Unión Soviética ocupada. Entre sus víctimas incluían judíos, romaníes (gitanos), y funcionarios del estado soviético y del partido comunista soviético e incluso asesinaron a miles de residentes de instituciones para personas con discapacidad mental y/o física. Muchos estudiosos creen que el asesinato sistemático de judíos en la Unión Soviética ocupada por los batallones de Einsatzgruppen y de la Orpo fue el primer paso de la "Solución Final" (United States Holoaust Memorial Museum) $\mathrm{y}$;

V. Die Wehrmacht que este era el nombre para el conjunto de las fuerzas armadas de la Alemania nazi que se dividía en el ejército, la marina y la fuerza aérea.

En relación a la etapa de la Polarización, las primeras víctimas en ser arrestados y asesinados de los cuales se pueden considerar dentro de los grupos moderados fueron a los opositores políticos como los comunistas y los social demócratas (Museo Memoria y Tolerancia, Ciudad de México, 2011., pág. 13). También, a los Testigos de Jehová, quienes fueron perseguidos por rehusarse a prestar lealtad al Estado. Empero, de los grupos perseguidos, fueron los únicos que tenían la opción de firmar una declaración renunciando a sus creencias, no obstante, muy pocos aceptaban esa oferta lo que conllevó a que desde 1935 a 1945 se encarcelaron a más de 10,000 Testigos de Jehová, ejecutaron a más de 200 por no prestar servicio militar y alrededor de 2,000 murieron en los campos de concentración (Museo Memoria y Tolerancia, Ciudad de México, 2011., pág. 14).

La etapa de la Preparación se inicia con el adoctrinamiento racista y antisemita a través de carteles, panfletos, radio, cine y diversos foros públicos (Museo Memoria y Tolerancia, Ciudad de México, 2011., pág. 7). Además, desde 1926 con el fin de inculcar la ideología nazi a las nuevas generaciones fueron creadas las Juventudes Hitlerianas $^{16}$. Iniciada la II GM, se empiezan a utilizar áreas para concentrar a los judíos y aislarlos del resto de la población, obligándolos a vivir en condiciones deplorables, llamadas: "ghettos", que se encontraban en las zonas más pobres y miserables de los países ocupados por Alemania como medida provisional mientras se decidía el futuro de los judíos (Museo Memoria y Tolerancia, 2013, pág. 9), mismo que fue decidido el 20 de enero de 1942, en la conferencia de Wannsee, en la cual se discutió cómo llevar a cabo la "Endlösung der Judenfrage" (Solución final a la pregunta o cuestión Judía), que era el nombre en código utilizado por los nazis para la destrucción deliberada y cuidadosamente planeada de los judíos en Europa.

En la misma se acordó, inter alía, utilizar una técnica de aniquilamiento más eficiente, económica y rápida diferente a la que se había comenzado a utilizar mediante fusilamientos masivos hace 7 meses antes en Europa del Este, e igualmente se acordó establecer campos de exterminio para llevar a cabo matanzas masivas (Museo Memoria y Tolerancia, Ciudad de México, 2011., pág. 11). Algunos de los eufemismos utilizados por los nazis en los campos de concentración para ocultar sus intenciones genocidas eran:

I. "Arbeit Macht Frei" (El trabajo libera) que era una frase que encontraba en la entrada de Auschwitz y otros campos;

II. "Selektion" (selección) que significaba elección de quién vive y quién muere;

III. "Sonderbehandlung" (trato especial) para decir: asesinato a la llegada;

IV. "Desinfizieren" (desinfección) que significa muerte mediante gas;

16 Se incorporaron miles de niños y jóvenes cuyo ingreso a esta organización se tornó obligatoria desde 1939, misma que logró agrupar alrededor de nueve millones de niños y jóvenes (Museo Memoria y Tolerancia, Ciudad de México, 2011., pág. 15). 
V. "Die Duschen" (las duchas) que significaba cámaras de gas;

VI. "Euthanasie" (eutanasia) para referirse a la matanza sistemática de aquellos alemanes que los nazis consideraban "indignos de vivir" debido a que padecían alguna enfermedad mental o impedimentos físicos;

VII. "Verbesserung" (mejoramiento) palabra para decir gaseo;

VIII. "Nacht und Nebel" (Noche y Neblina) que era el código para referirse a los prisioneros que serían aniquilados sin dejar rastro, entre otros eufemismos.

Las etapas de Persecución y Exterminio concurren de forma paralela. Después de la conferencia de Wannsee en donde Reinhard Heydrich $^{17}$, decide que millones de judíos serían finalmente sometidos a la "solución final", con las Leyes de Núremberg como base para determinar quién era judío ${ }^{18}$; los ghettos comenzaron a ser evacuados para transportar a los judíos a los campos de exterminio, allí, separaban a las mujeres de los hombres, mismos que tenían que pasar delante de los médicos de la SS, estos decidían con el movimiento del dedo, quiénes serían exterminados en las cámaras de gas y quiénes quedarían como prisioneros del campo que eran asesinados con la menor provocación (Museo Memoria y Tolerancia, 2013, pág. 12).

Todas las personas que no eran consideradas útiles para los nazis, como ancianos, personas con alguna discapacidad, mujeres embarazadas, niños y enfermos, eran seleccionadas para llevarlas a

17 Segundo en el mando después del jefe de las SS Heinrich Himmler y director de la Oficina de Seguridad Principal del Reich (Reichsführer) (United States Holocaust Memorial Museum).

18 Las leyes de Núremberg, como se las conoció, no definían a un "judío" como alguien que tenía determinadas creencias religiosas, sino que cualquier persona que tuviera tres o cuatro abuelos judíos, era definida como judía, independientemente de si se identificaba como judía o pertenecía a la comunidad religiosa judía. Muchos alemanes que no habían practicado el judaísmo durante años fueron presa del terror nazi. Incluso aquellos que tenían abuelos judíos pero que se habían convertido al cristianismo eran definidos como judíos (United States Holocaust Memorial Museum). las cámaras de gas (Museo Memoria y Tolerancia, 2013, pág. 12). Los campos nazis de exterminio tenían como finalidad el asesinato en masa y a diferencia de los campos de concentración, que sevían primariamente como centros de detención y trabajo, los campos de exterminio eran "fábricas de muerte" en dónde más de tres millones de judíos fueron asesinados con gas y fusilamiento (United States Holocaust Mmeorial Museum).

En concomitancia con la etapa de la simbolización, en los campos de concentración nazis poseían un sistema de marcaje de prisioneros basado principalmente en triángulos invertidos, los cuales estaban hechos de tela y se cosían sobre las chaquetas y camisas de los prisioneros, mismas que eran obligatorias y tenían significados concretos que servían para distinguir las razones por las que el prisionero había ingresado al campo, que eran, inter alia, por ser homosexual, testigo de Jehová, gitano o judío. Igualmente, se les colocaba una letra en el centro del triángulo para denotar el país de origen. En otros campos como en el de Auschwitz, se les tatuaba un número de serie. Se estima que en el Holocausto murieron de 5, 600,000 a 6, 000,000 de judíos; de 222,000 a 250,000 gitanos; 12,000 homosexuales; 2,500 Testigos de Jehová, y; miles de prisioneros de guerra soviéticos, polacos católicos, serbios, y; alemanes con discapacidad o por causas políticas, religiosas o por ser parte de la resistencia (Museo Memoria y Tolerancia, 2013, pág. 16).

La etapa de la Negación ya se podía identificar antes de la caída del imperio nazi desde 1943 en un discurso a los generales de la SS en Poznan, Heinrich Himmler, líder del Reich (Reichsführer) de la SS, comenta que el asesinato en masa de judíos europeos se mantendrá en secreto y nunca deberá quedar registrado, (United States Holocaust Memorial Museum) Esas directrices fueron ejecutadas a finales de 1944, previendo su derrota, intentaron desesperadamente evacuar los campos de concentración para no dejar testigos de sus atrocidades. Sin embargo, aun deseaban culminar con la "Solución Final", por lo que 
obligaron a los prisioneros a salir de los campos en marchas forzadas hacia el interior de Alemania con el objeto de agotarlos y que murieran en las difíciles condiciones del invierno e iban ejecutando a aquellos que se detenían o retrasaban, a lo que se le llamo "Marchas de la muerte" (Museo Memoria y Tolerancia, 2013, pág. 15).

Para ocultar las pruebas de su aniquilación de judíos europeos, los alemanes y sus colaboradores destruyeron las pruebas de las fosas comunes en los centros de exterminio de Belzec, Sobibor y Treblinka, y en miles de sitios de fusilamiento en masa en toda la Polonia ocupada por los alemanes, la Unión Soviética ocupada por los alemanes y Serbia, incluido Babi Yar, en una operación llamada en código "Aktion 1005" (United States Holocaust Memorial Museum). A pesar de que el Holocausto es uno de los hechos mejores documentados en la historia, muchos estudiosos se han esmerado por negar los hechos establecidos del genocidio de judíos europeos por parte de los nazis, afirmando, inter alia, que el asesinato de aproximadamente seis millones de judíos durante la II GM nunca sucedió; que el diario de Ana Frank es apócrifo, que los nazis no tenían ninguna política oficial o intención de exterminar a los judíos; que las cámaras de gas en el campo de exterminio de Auschwitz-Birkenau nunca existieron (United States Holocaust Memorial Museum), entre otras razones. En la actualidad en algunos países negar el Holocausto se ha tipificado como un delito por ejemplo en Francia en la ley "Gayssot" de 1990 y en Alemania en su Código Penal Alemán "Strafgesetzbuch", articulo 130, párrafo (3).

\section{JUICIOS INTERNACIONALES Y NACIONALES QUE SE LLEVARON A CABO PARA IMPUTAR RESPONSABILIDAD PENAL A LOS PERPETRADORES}

El 30 de octubre de 1943 en la conferencia de Moscú, el presidente estadounidense Franklin Delano Roosevelt, el primer ministro británico Winston Churchill y el presidente del consejo de ministros soviético Lósif Stalin, declararon que los oficiales alemanes y nazis que fueran responsables o hubieren participado en los crímenes o atrocidades serían devueltos a los países en los que los hubieren cometido para ser juzgados y castigados de conformidad con las leyes de los Estados liberados y que los alemanes que hubieren cometido crímenes que no tuvieren una localización geográfica delimitada serian castigados por medio de la fórmula que los aliados decidieran (Guevara \& del Maso, 2005, pág. 9).

En correspondencia a esa fórmula, el obstáculo que existía para el enjuiciamiento de dichas atrocidades era que las mismas no estaban cubiertas por el Derecho Internacional vigente en la época, por lo que había que fundamentar la competencia y el Derecho aplicable a las mismas. Por ello, en febrero de 1945, en la Conferencia de Yalta se decide crear un tribunal para juzgar a las más altas jerarquías del régimen nazi (Universitat de les illes Belears) y el 8 de agosto de 1945 los gobiernos de los EUA, del RU de la Gran Bretaña e Irlanda del Norte, de la URSS y el gobierno provisional de Francia, celebraron el Acuerdo de Londres en el cual se estipuló que se juzgarían a los responsables de haber cometido crímenes sin ubicación geográfica definida por un Tribunal Internacional Militar, creado de conformidad con su carta constitutiva anexa, mismo que tendría su sede en Núremberg, Alemania, por ello se le llamó el "Tribunal Militar Internacional de Núremberg" (En adelante TIMN). El tribunal estaba compuesto por cuatro jueces designados por cada uno de los países signatarios del Acuerdo de Londres (Guevara \& del Maso, 2005, pág. 9). Su competencia era la siguiente:

1. En ratione materiae, en el artículo 6 literales a), b) y c) se estableció que se juzgarían: Crímenes contra la Paz ${ }^{19}$; Crímenes de

19 a) CRIMENES CONTRA LA PAZ: A saber, planificar, preparar, iniciar o librar guerras de agresión, o una guerra que constituya una violación de tratados, acuerdos o garantías internacionales, o participar en planes comunes o en una conspiración para lograr alguno de los objetivos anteriormente indicados 
Guerra $^{20}$, y; Crímenes contra la Humanidad ${ }^{21}$. Asimismo, en el artículo 6 párrafo último se incluyó el cargo de Conspiración para cometer los supra crímenes.-

2. En ratione temporis, tendría competencia a crímenes ocurridos durante la II GM, y;

3. En ratione personae, sobre personas físicas individuales y además sobre organizaciones (Guevara \& del Maso, 2005, pág. 9 y 10). El cargo de conspiración, y la decisión de juzgar organizaciones alemanas y nazis específicas como acusados ante el tribunal permitió futuros juicios contra todo individuo perteneciente a estas organizaciones criminales (United States Holocaust Memorial Museum).

También es importante mencionar que en el estatuto del TIMN en su art. 7 estableció conducentemente que, "el cargo oficial de los acusados, ya sean Jefes de Estado o funcionarios a cargo de Departamentos del Gobierno no les exonerará de las responsabilidades ni servirá para atenuar la pena"; y en el art 8 que el "hecho de que el Acusado actuara obedeciendo órdenes de su gobierno o de un superior no le exonerará de responsabilidad, pero podrá considerarse un atenuante al determinar la condena si el Tribunal estima que la justicia así lo exige".

20 b) CRIMENES DE GUERRA: A saber, violaciones de las leyes o usos de la guerra. En dichas violaciones se incluye el asesinato, los malos tratos o la deportación para realizar trabajos forzados o para otros objetivos en relación con la población civil de un territorio ocupado o en dicho territorio, el asesinato o malos tratos a prisioneros de guerra o a personas en alta mar, el asesinato de rehenes, el robo de bienes públicos o privados, la destrucción sin sentido de ciudades o pueblos, o la devastación no justificada por la necesidad militar, sin quedar las mismas limitadas a estos crímenes.

21 c) CRIMENES CONTRA LA HUMANIDAD: A saber, el asesinato, la exterminación, esclavización, deportación y otros actos inhumanos cometidos contra población civil antes de la guerra o durante la misma; la persecución por motivos políticos, raciales o religiosos en ejecución de aquellos crímenes que sean competencia del Tribunal o en relación con los mismos, constituyan o no una vulneración de la legislación interna de país donde se perpetraron.
El 6 de octubre de 1945 los cuatro fiscales principales $^{22}$ del TIMN, presentaron acusaciones contra 24 oficiales nazis de alto rango. Hitler ni Heinrich Himmler fueron acusados por que se suicidaron al término de la guerra. Durante el juicio, la fiscalía presentó más de tres mil toneladas de documentos que evidenciaban los crímenes perpetrados por los nazis, entre ellos el protocolo de la Conferencia de Wannsee y los informes de los Einsatzgruppen (Museo Memoria y Tolerancia, Ciudad de México, 2011., pág. 26) También, se presentaron acusaciones en contra de seis organizaciones catalogadas de criminales ${ }^{23}$. El 1 de octubre de 1946 el TIMN dictó sentencia condenando a muerte a 12 acusados ${ }^{24}$; tres a cadena perpetua ${ }^{25}$; cuatro reciben sentencias que van desde los 10 a los 20 años $^{26}$, y; el tribunal absolvió a tres de los acusados ${ }^{27}$.

Las sentencias de muerte se llevan a cabo el 16 de octubre de 1946, con dos excepciones: Goering se suicidó poco antes de la fecha de su ejecución y Bormann continuó desaparecido. Los otros 10 acusados son ahorcados, sus cuerpos cremados y las cenizas depositadas en el río Iser. Los siete principales criminales de guerra sentenciados a reclusión son enviados a la prisión de Spandau en Berlín (United States Holocaust Memorial Museum).

22 Robert H. Jackson (EUA), Francois de Menthon (Francia), Roman A. Rudenko (Unión Soviética) y Sir Hartley Shawcross (Gran Bretaña).

23 Partido laboral nacionalsocialista alemán (Nationalsozialistische Deutsche Arbeiterpartei NSDAP), las tropas de asalto (Sturmabteilung [SA]), el Escuadrón de Protección (Schutzstaffel [SS]), el Gobierno del Reich (Reichsregierung), el Cuerpo de Generales y altos Mandos de las Fuerzas Armadas (Generalstab und Oberkommando der Wehrmacht [OKW]), la Policía secreta del Estado (Geheime Staatspolizei [Gestapo]), y el Servicio de Seguridad (Sicherheitsdienst [SD]. (Ambos \& Meyer, 2009, pág. 440)

24 Goering, Ribbentrop, Keitel, Kaltenbrunner, Rosenberg, Frank, Frick, Streicher, Sauckel, Jodl, SeyssInquart y Bormann. 25 Hess, el ministro de economía Walther Funk y Raeder 26 Doenitz (10), Schirach (20), Speer (20) y Neurath (15).

27 Hjalmar Schacht (ministro de economía), Franz von Papen (político alemán que desempeñó un papel importante en la designación de Hitler como canciller) y Hans Fritzsche (jefe de prensa y radio). 
La SS, la SD, la Gestapo y el cuerpo dirigente del NSDAP (Nationalsozialistische Deutsche Arbeiter Partei-Partido Nacionalsocialista Obrero Alemán conocido como partido Nazi) fueron calificados de criminales. Sin embargo, La determinación de la culpabilidad individual de cada uno de los miembros la dejó en cambio para procesos posteriores (Ambos \& Meyer, 2009, pág. 440).

El 20 de diciembre de 1945, el Consejo de Control para Alemania promulgó la Ley N. ${ }^{\circ} 10$ para procesar a los criminales de guerra y otros criminales similares que no fueron juzgados por el TIMN, los llamados "juicios posteriores de Núremberg". En esta ley se acordó que los tribunales de los aliados, en sus respectivas zonas de ocupación de Alemania, podrían conocer los crímenes contra la paz, crímenes de guerra, crímenes contra la humanidad y la pertenencia a las categorías de un grupo u organización declarada como criminal por el TIMN (Guevara \& del Maso, 2005, pág. 10 y 11).

Bajo esta Ley, los estadounidenses, británicos y franceses llevaron juicios en contra de alemanes que hubieren cometido crímenes bajo su competencia de conformidad con la Ley 10. En total, Estados Unidos imputó a 183 acusados en 12 juicios posteriores de Núremberg ${ }^{28}$ que tuvieron como resultado 12 penas de muerte, 8 cadenas perpetuas y 77 penas de encarcelamiento; y otros acusados fueron absueltos. (United States Holoaust Museum) Como resultado de la clemencia de posguerra, las autoridades que revisaron los casos posteriormente conmutaron muchas condenas por períodos más breves y liberaron a algunos individuos por el tiempo de condena ya cumplido (United States Holoaust Museum).

28 Los 12 juicios posteriores fueron: Juicio n. ${ }^{\circ} 1$ : El caso médico; Juicio n. ${ }^{\circ}$ 2: El caso Milch; Juicio n. ${ }^{\circ}$ 3: El caso de los jueces; Juicio n. ${ }^{\circ}$ 4: El caso Pohl; Juicio n. ${ }^{\circ}$ 5: El caso Flick; Juicio n. ${ }^{\circ}$ 6: El caso de la I.G. Farben; Juicio n. ${ }^{\circ}$ 7: El caso de los rehenes; Juicio n. ${ }^{\circ} 8$ : El caso RUSHA; Juicio n. ${ }^{\circ}$ 9: El caso Einsatzgruppen (escuadrones móviles de la muerte); Juicio n. ${ }^{\circ}$ 10: El caso Krupp; Juicio n. ${ }^{\circ} 11$ : EL caso de los ministerios; Juicio n. ${ }^{\circ} 12$ : El caso del Alto Comando.
Este tribunal ad hoc al igual que el Tribunal Internacional Militar del Lejano Oriente (Tribunal de Tokio) recibieron varias críticas que son acertadas, entre ellas que eran mecanismos de justicia de los vencedores; que al ser creados ex post facto, es decir, posteriormente a los hechos, aplicando los tipos penales sobre los que tuvieron competencia ambos tribunales, se incumplió el principio de legalidad o nullum crimen, nulla poena sine lege praevia stricta et scripta, ya que algunas de las conductas castigadas no constituían delito según el Derecho Nacional o Internacional vigente en el momento de su comisión ${ }^{29}$, y que apenas un pequeño porcentaje de los criminales enfrentaron la justicia. Empero, el legado de estos juicios es invaluable, pues gracias a estos procesos se inició la documentación de los hechos ocurridos, se logró quitarle a los tribunales nacionales el monopolio de la jurisdicción penal para llevar a personas naturales ante la justicia a quienes cometan crímenes contra el derecho internacional (Guevara \& del Maso, 2005, pág. 15).

Estos juicios, incluidas sus cartas y sentencias, por su relevancia y el enorme precedente que legaron, llevaron a la ONU en diciembre de 1946 a confirmar los principios de Derecho Internacional reconocidos por el estatuto del TIMN y las sentencias de dicho Tribunal, que al transcurrir de los años se tradujo en lo que la Comisión de Derecho Internacional aprobó en 1950 como los "Principios de Derecho Internacional reconocidos por el Estatuto y por las sentencias del Tribunal de Nuremberg", ${ }^{30}$ y; además

29 “...Los tribunales negaron sin embargo una violación a este principio con el fundamento iusnaturalista y de derechos humanos de que los acusados habrían violado principios jurídicos fundamentales reconocidos por todos los pueblos civilizados de la tierra y que estos principios ya existían cuando los hechos se cometieron. El IMG entendió el principio de irretroactividad de la ley como un principio de justicia en el sentido de un hecho de confi anza subjetivo, y en sentido objetivo como expresión de un orden jurídico dinámico, que no tendría su fuente en el derecho positivo, sino en el derecho consuetudinario y natural, y que se debe adaptar "mediante permanente ajuste a las necesidades de un mundo cambiante" (Ambos \& Meyer, 2009, pág. 441)

30 “...Los tribunales negaron sin embargo una violación a este principio con el fundamento iusnaturalista y de derechos humanos de que los acusados habrían violado principios jurídicos fundamentales reconocidos por todos los pueblos civilizados de 
estas experiencias sirvieron de base para la creación de la CPI.

Cabe mencionar que los juicios a los nazis continuaron en Alemania y en otros países como en Israel en donde se enjuició a Adolf Eichmann, quien había ayudado en la planificación y la realización de las deportaciones de millones de judíos; tras ser ubicado y secuestrado en Argentina y trasladado a Israel, fue enjuiciado hallado culpable y ejecutado en 1962. Las cortes de Alemania comenzaron a trabajar, en algunos casos y de 1945 a 1969, casi 80.000 alemanes habían sido investigados y más de 6.000 habían sido sentenciados. No obstante, uno de los mayores problemas con respecto a los juicios de criminales de guerra en Alemania, sobre todo en la ex República Federal Alemana, era que las sentencias resultaban exageradamente clementes en proporción a los crímenes cometidos (Holocaust Museum Houston).

En relación a las amnistías tras la devolución de la competencia ilimitada de la persecución penal a los tribunales alemanes en 1951, en los cuales las condenas por hechos violentos nacionalsocialistas eran regresivas y aplicaban solo el derecho penal alemán se instalaba un sentimiento de reinicio a una mentalidad de punto final por lo que se empezaron a dar muchas amnistías, que incluso una parte fue a través de los aliados por medio de indultos y por otra parte por medio del legislador alemán mediante las llamadas leyes de impunidad (Straffreichitsgesetze) ${ }^{31}$. Por otra parte, la prescripción de la persecución penal ya había la tierra y que estos principios ya existían cuando los hechos se cometieron. El IMG entendió el principio de irretroactividad de la ley como un principio de justicia en el sentido de un hecho de confi anza subjetivo, y en sentido objetivo como expresión de un orden jurídico dinámico, que no tendría su fuente en el derecho positivo, sino en el derecho consuetudinario y natural, y que se debe adaptar "mediante permanente ajuste a las necesidades de un mundo cambiante" (Ambos \& Meyer, 2009, pág. 441)

31 La primera, de 1949, preveía la impunidad para hechos cometidos antes del 15 de septiembre de 1949 para los que a su vez estuvieran previstas penas privativas de la libertad no mayor de seis meses de prisión. Una segunda ley, de 1954, declaró impunes determinados hechos cometidos en la etapa final de la guerra que previeran penas de hasta tres años. (Ambos \& Meyer, 2009, pág. 443 y 444$)$ llevado en 1950 a que solo pudieran seguir siendo perseguidos los delitos de asesinato, homicidio y lesiones graves en ese contexto, numerosos ex miembros del NSDAP o de otras organizaciones del régimen nacionalsocialista, así como personas que habían trabajado en la administración o en el sistema judicial del Estado nazi, regresaron a sus cargos en los años cincuenta, o fueron de diversas maneras integradas en la construcción administrativa o judicial de la República Federal Alemana (Ambos \& Meyer, 2009, pág. 444).

La jurisprudencia de esta época se caracterizó por una parte por el reemplazo del tipo penal del asesinato por el de homicidio y, por otra, por el creciente número de condenas por participación en lugar de coautoría. (Ambos \& Meyer, 2009, pág. 445). Entre 1960 y 1979 se extendieron cada vez más los plazos de prescripción para los hechos violentos nacionalsocialistas aún pendientes, hasta que finalmente en 1979 se declaró la imprescriptibilidad del asesinato (Ambos \& Meyer, 2009, pág. 446).

\section{¿TIENE COMPETENCIA LA CPI PARA EJERCER SUS FUNCIONES DE INVESTIGACIÓN, PROCESAMIENTO Y SANCIÓN DE LOS RESPONSABLES DE LOS CRÍMENES TIPIFICADOS EN EL ESTATUTO DE ROMA Y PERPETRADOS DURANTE EL HOLOCAUSTO?}

Para determinar la competencia de la CPI se deben tomar en consideración los siguientes criterios: Competencia en razón de la materia (I), en razón del territorio (II), en razón de las personas (III), y; en razón del tiempo (IV) (Comisión Andina de Juristas, CAJ, 2004, pág. 21). En este orden de ideas, si analizamos la competencia en razón del tiempo y en el supuesto que no se hubiese creado un tribunal internacional militar ad-hoc para tales efectos, es importante tomar en cuenta que el ER que crea la CPI, fue adoptado el 17 de julio de 1998 y entró en vigor el 1 de julio de 2002, de acuerdo a su artículo $126^{32}$. Asimismo, la competencia

32 Estatuto de Roma, artículo 126, numerales 1 y 2: 1 . El presente 
en razón del tiempo es irretroactiva de acuerdo lo establecido en su art. 11 porque está limitada en el tiempo a la fecha de la entrada en vigor general del ER (1 de julio de 2002) por lo que la CPI no podrá conocer de ningún crimen que se haya cometido con anterioridad a la entrada en vigor del ER, sin importar su gravedad.

En el caso de los Estados que ratificaron el ER después de su entrada en vigor general, a pesar que tiene la posibilidad de realizar una declaración en la que autorice a la CPI para conocer de los crímenes cometidos con anterioridad a la entrada en vigor del tratado para dicho Estado, esta declaración nunca podrá abarcar los crímenes cometidos con anterioridad a la entrada en vigor general del ER; en otras palabras, aun cuando el Estado en cuestión así lo acepte, la competencia temporal de la CPI tiene un límite absoluto: el 1 de julio de 2002, es otros términos, la CPI es incompetente para conocer los crímenes ocurridos durante el Holocausto.

\section{HERRAMIENTAS \\ NACIONALES INTERNACIONALES DE PREVENCIÓN QUE SE UTILIZARON DURANTE Y DESPUÉS DEL CONFLICTO}

\section{III.I. Las Herramientas de Prevención Nacionales durante el conflicto}

Durante este conflicto no fue posible la materialización de herramientas de prevención, porque las políticas económicas del régimen nazi estaban orientadas a generar pobreza, desigualdad, creciente concentración empresarial como efecto

Estatuto entrará en vigor el primer día del mes siguiente al sexagésimo día a partir de la fecha en que se deposite en poder del Secretario General de las Naciones Unidas el sexagésimo instrumento de ratificación, aceptación, aprobación o adhesión. 2. Respecto de cada Estado que ratifique, acepte o apruebe el presente Estatuto o se adhiera a él después de que sea depositado el sexagésimo instrumento de ratificación, aceptación, aprobación o adhesión, el Estatuto entrará en vigor el primer día del mes siguiente al sexagésimo día a partir de la fecha en que haya depositado su instrumento de ratificación, aceptación, aprobación o adhesión. de la "arianización". En materia de gobernanza y seguridad, las leyes que se promulgaron durante el régimen trataron de sustentar el odio racial. De este modo, el racismo, antisemitismo, la discriminación, la violencia e incluso el asesinato se efectuaron dentro de un marco estrictamente legal, (Museo Memoria y Tolerancia, 2013, pág. 7) lo que generó mayor impunidad. Asimismo, no hubo medidas sociales porque el régimen nazi se apoderó del control absoluto de la literatura, la prensa, la radio, el teatro, el cine, la educación y de todas las manifestaciones artísticas en Alemania, para propagar el anticomunismo, la xenofobia y el antisemitismo.

\section{III.II. Las Herramientas de Prevención Internacionales durante el conflicto}

Las herramientas utilizadas no fueron muy eficientes; en enero de 1944 se estableció el Comité para Refugiados de Guerra, con el fin de salvar a las víctimas de la persecución nazi (Holocaust Museum Houston). No obstante, antes de a esa fecha se hizo muy poco al respecto. El 17 de diciembre de 1942, los Aliados publicaron una declaración en la que reprobaban las atrocidades realizadas por los nazis en contra de los judíos.

Además, no hubo intentos de convocar a la población local europea a que se abstuviera de colaborar con los nazis en el asesinato sistemático de judíos $^{33}$. Asimismo, el Presidente Estadounidense, Franklin Roosevelt, convocó, en 1938, a una conferencia Internacional, en Evián, Francia, para analizar el problema de los refugiados judíos, en la cual, representantes de 32 países manifestaron su consternación por la suerte de los refugiados, pero ninguno se ofreció a recibir una migración

33 Incluso luego del establecimiento del Comité para Refugiados de Guerra y de la introducción de diversos planes de rescate, los Aliados se negaron a bombardear el campo de exterminio de Auschwitz y/o las líneas de ferrocarril que llegaban a dicho campo, a pesar de que para ese entonces sus bombarderos se encontraban disparando sobre fábricas muy cercanas al campo y tenían pleno conocimiento de su existencia y función. (Holocaust Museum Houston) 
masiva (Museo Memoria y Tolerancia, Ciudad de México, 2011., pág. 14) a excepción de Republica Dominicana que si estaba dispuesta a modificar sus normas inmigratorias (Holocaust Museum Houston).

En dicha conferencia, se estableció el Comité Intergubernamental de Refugiados y a través de éste, en 1939 se iniciaron negociaciones con importantes oficiales alemanes con la intención de acordar la reubicación de un gran número de judíos alemanes, pero estas iniciativas fracasaron (Holocaust Museum Houston). Asimismo, diversas organizaciones intentaron facilitar la emigración de los judíos (y no-judíos perseguidos como si fueran judíos) de Alemania. Entre las más activas se encontraban la Jewish Agency for Palestine (Agencia Judía para Palestina), el American Jewish Joint Distribution Committee (Comité de Distribución Conjunta JudeoEstadounidense), el HICEM, el Central British Fund for German Jewry (Fondo Central Británico para la Comunidad Judía de Alemania), el Reichsvertretung der Deutschen Juden (Representación en el Reich de Judíos Alemanes), y otros grupos no judíos como la Comisión Superior de la Liga de las Naciones para Refugiados --judíos y no judíos-- provenientes de Alemania, y el American Friends Service Committee (Comité de Servicios de Amigos de Estados Unidos) (Holocaust Museum Houston).

Entre los programas lanzados estaba el "Acuerdo de Transferencia" celebrado entre la Agencia Judía y el gobierno alemán, que permitía a aquellos que inmigraban a Palestina transferir sus fondos a ese país junto con las importaciones de mercaderías alemanas a Palestina y otros esfuerzos se centraron en brindar una nueva capacitación a futuros emigrantes a fin de incrementar el número de personas aptas para el otorgamiento de visas, en vista que algunos países prohibían el ingreso de quienes ejercían ciertas profesiones (Holocaust Museum Houston).

La Cruz Roja Internacional (En adelante CRI), durante la II GM realizó algunas actividades para ayudar a las personas judías de la persecución nazi, entre ellas, se envió envases de alimentos a las víctimas del conflicto a excepción de los habitantes de los ghettos y de los campos por no permitírseles (Holocaust Museum Houston). También, aunque las organizaciones judías hicieron varias solicitudes a la CRI para que se pronunciase contra la aniquilación masiva de judíos y no judíos en los campos e intervenir en su defensa, la CRI se negó a protestar públicamente sobre lo solicitado argumentando que cualquier accción podría resultar en detrimento de su bienestar (Holocaust Museum Houston). luego de la intervención de distinguidas figuras, como el presidente Franklin Roosvelt y el Rey de Suecia, la CRI apeló a Miklós Horthy, regente de Hungría, para que detuviera la deportación de judíos húngaros, e instó que se le permitiera visitar los campos de concentración, y una delegación fue autorizada a visitar el "ghetto modelo" de Terezin (Theresienstadt) sin embargo, los alemanes mejoraron las condiciones del ghetto previo a la visita (Holocaust Museum Houston).

\section{III.III. Las Herramientas de Prevención Nacionales después del conflicto}

Estas son más visibles, sobre todo en materia de Justicia Transicional o como los alemanes la denominan de "Vergangenheitsbewältigung", es decir, de superación del pasado o como el estadounidense Michael Walzer, lo denomina con el enunciado en latín jus post bellum, es decir, el derecho, o la justicia, tras la guerra (Villa, 2007, pág. 1).

En este orden de ideas, la Justicia Transicional es definido por el Centro Internacional para la Justicia Transicional ${ }^{34}$ (ICTJ siglas en inglés) como el conjunto de medidas judiciales y políticas que diversos países han utilizado como reparación por las violaciones masivas de derechos humanos. Entre ellas figuran las acciones penales, las comisiones de la verdad, 34 El ICTJ es una organización internacional sin ánimo de lucro especializada en la justicia en periodos de transición, trata de ayudar a sociedades en proceso de transición a enfrentarse al legado de violaciones masivas de los derechos humanos y a desarrollar la confianza ciudadana en la capacidad de las instituciones públicas para proteger esos derechos. 
los programas de reparación y diversas reformas institucionales (Centro Internacional para la Justicia Transicional).

El ITCJ señala que las víctimas de violaciones de los derechos humanos no pueden olvidar y los Estados tienen el deber de preservar la memoria de esos crímenes, por el cual los monumentos, los museos y los actos conmemorativos son iniciativas educativas indispensables para el establecimiento de un registro irrefutable y para evitar la repetición de los abusos (Centro Internacional para la Justicia Transicional).

Paul Van Zyl señala que la Justicia Transicional ${ }^{35}$ se entiende como el esfuerzo por construir paz sostenible tras un periodo de conflicto, violencia masiva o violación sistemática de los derechos humanos, cuyo objetivo implica llevar a juicio a los perpetradores, revelar la verdad acerca de crímenes pasados, brindar reparaciones a las víctimas, reformar las instituciones abusivas y promover la reconciliación (Comisión de Amnistía del Ministerio de Justicia de Brasil, ICTJ, 2011).

Atendiendo a estas definiciones, se identificara como se materializó la Justicia Transicional durante el Holocausto, es decir, cuáles fueron las medidas para obtener Justicia, verdad, reparación, reformas institucionales, memoria y reconciliación.

Como mencionan Kai Ambos y Nils Meyer-Abich (2009):

Alemania tuvo que superar la transición de un sistema totalitario a un sistema democrático en dos oportunidades durante el siglo pasado: por una parte, durante la lenta elaboración de las injusticias e ilegalidades propias del

35 En relación a esta definición de Justicia Transicional, en el manual: "Justicia Transicional, manual para américa latina", señala en una nota al pie de página que deriva en gran parte de la articulación por parte de la Corte Interamericana de Derechos Humanos de las obligaciones legales de un Estado después de un periodo de graves violaciones de los Derechos Humanos, en el caso de Velásquez Rodríguez Vs Honduras. (Comisión de Amnistía del Ministerio de Justicia de Brasil, ICTJ, 2011, pág. 47 y 49) nacionalsocialismo desde el fin de la segunda guerra mundial (8 de mayo de 1945); por otra parte, durante la elaboración de la criminalidad propia del sistema de la República Democrática Alemana (RDA) desde la caída del muro de Berlín (9 de noviembre de 1989) y la consiguiente adhesión de la RDA a la República Federal de Alemania (RFA) (3 de octubre de 1990). (pág. 435)

Por lo que únicamente se hará alusión al primer proceso de transición, exponiéndose cada uno de los componentes de la Justicia Transicional:

1. Justicia: Las acciones penales en Alemania ante sus propios tribunales se dan en 1945 por actos violentos nacionalsocialistas y en 1952 el poder jurisdiccional fue adscrito completamente a la justicia alemana y así todos los procesos tuvieron lugar de forma exclusiva ante tribunales alemanes (Ambos \& Meyer, 2009, pág. 438).

2. Verdad: En 1958, en la ex-República Federal de Alemania, establecieron una agencia especial en Ludwigsburg a fin de colaborar con la investigación de los crímenes cometidos por alemanes fuera de Alemania y desde su fundación, participó en cientos de investigaciones importantes (Holocaust Museum Houston). La Oficina Central de las Administraciones Judiciales de los Länder para el Esclarecimiento de Crímenes del Nacionalsocialismo (Zentrale Stelle der Landesjustizverwaltung zur Aufklärung nationalsozialistischer Verbrechen), permitió por primera vez llevar adelante una persecución penal sistemática, centralizada e independiente de la predisposición de denuncia de la población y realizó investigaciones preliminares por su cuenta pero que para la presentación de denuncia entregaba el caso a la Fiscalía (Ambos \& Meyer, 2009, pág. 445 y 446).

3. Reparación: También, se efectuaron 
numerosas acciones de reparación e indemnización, así como medidas de rehabilitación entre ellas:

a. Sanya Romeike (2016) sobre las medidas de reparación señala que,

La indemnización por los daños y las pérdidas causadas por la guerra fueron reguladas por los aliados en los acuerdos de Potsdam en 1945. En ellos se decidió que las reclamaciones de reparación no se satisfarían mediante el pago de dinero, sino con el desmantelamiento de la industria e infraestructura alemanas. El territorio de reparación se dividió: la Unión Soviética y Polonia fueron compensadas con la toma de la zona de ocupación soviética, mientras que las potencias occidentales y todos los demás estados beneficiarios fueron indemnizados con la zona occidental. Además, los fondos alemanes depositados en el extranjero fueron confiscados $y$ aprovechados, de los cuales la Unión Soviética tomó la fortuna del "este» y las potencias occidentales, la del "oeste". Adicionalmente, la flota marina mercante alemana y sus reservas de oro (también las del extranjero) fueron confiscadas. (pág. 28 y 29)

b. "En 1946 fueron comprometidos pagos de reparación a 19 países y a partir de 1947 se sancionaron leyes de reintegro en las correspondientes zonas ocupadas" (Ambos \& Meyer, 2009, pág. 438).

c. En 1952 el Estado Alemán en un acuerdo con el Estado israelí y organizaciones judías se comprometió al pago de 3.500 millones de marcos alemanes (Ambos \& Meyer, 2009, pág. 438).

d. Kai Ambos y Nils Meyer-Abich (2009) señalan que, en los años cincuenta se sancionaron numerosas leyes de reparación y recomposición que contenían compromisos de desembolsos en favor de las personas que habían sido perseguidas por el régimen nacionalsocialista por motivos racistas, religiosos y políticos, así como en favor de familias judías que bajo el dominio nacionalsocialista habían sido víctimas de expropiaciones (pág. 438). De igual manera, estos autores indican que, la rehabilitación de los condenados por tribunales nacionalsocialistas se puede identificar en los años cuarenta y fue perfeccionada por regulaciones de los distintos estados federados (Länder) en las décadas subsiguientes y, en 1998 con la ley para la abolición de sentencias injustas se llegó a sancionar una ley federal por la cual numerosas sentencias fueron anuladas en forma general (Ambos \& Meyer, 2009, pág. 438).

e. Para principios de 1998 se han efectuado pagos reparatorios por un valor aproximado de 102.000 millones de marcos. (Ambos \& Meyer, 2009, pág. 439)

f. Sehan hecho disculpas públicas, verbigracia, en abril de 1990, el Parlamento Alemán reconoció públicamente la responsabilidad de la República Democrática Alemana para el Holocausto en nombre de sus ciudadanos, y pidió a Israel y a todos los Judíos perdón por las deficiencias en el trato con el pasado (Romeike, 2016, pág. 43) y en el 2000 el presidente alemán, Johannes Rau, pidió perdón ante el Parlamento de Israel por la responsabilidad de su país en la muerte de seis millones de judíos durante el periodo nazi (Sales, 2000).

4. Reformas Institucionales: Se realizaron diversas medidas, las cuales Kai Ambos y Nils Meyer-Abich (2009) las han nombrado de desnazificación, (pág. 439). Las medidas de desnazificación que identifican estos autores son las siguientes: 
a. Se derogaron en primer término las leyes nacionalsocialistas más importantes y se suprimieron organizaciones e instituciones nacionalsocialistas como el Tribunal del Pueblo $^{36}$ y los tribunales especiales que trataban asuntos penales de carácter político. (Ambos \& Meyer, 2009, pág. 439)

b. Se desvinculó de cargos públicos a personas incriminadas y algunas de ellas fueron encarceladas (Ambos \& Meyer, 2009, pág. 439).

c. Kai Ambos y Nils Meyer-Abich (2009) señalan que,

[S]e redujeron las competencias de las autoridades y los tribunales alemanes en la tramitación de asuntos nacionalsocialistas. Al mismo tiempo, numerosas personas recorrían los campos de internación y, mediante encuestas, la población fue dividida en diferentes categorías de recriminación y sometida a dictámenes tribunalicios cuasipenales (especialmente en la zona estadounidense). (pág. 439)

d. Se efectuaron medidas educativas por ejemplo mediante la proyección de material fílmico sobre los crímenes del nacionalsocialismo (Ambos \& Meyer, 2009, pág. 439).

36 Volksgerichtshof (Tribunal del pueblo) fue un tribunal creado mediante la ley: "Gesetz zur Aburteilung von Hochund Landesverrat" (Ley para el enjuiciamiento de alta traición y traición a la patria) de 24 de abril de 1934, y tras la rendición alemana, el Tribunal Popular, que formuló aproximadamente 5,200 condenas a muerte por un total de 18,000 sentencias, fue disuelto por la Proclamación No. 3 del Consejo de Control Aliado del 20 de octubre de 1945. El Tribunal Popular era un tribunal político para eliminar a los opositores del régimen nazi. Con el principio "Recht ist, was dem Volke nützt” (El Derecho es lo que beneficia al pueblo), la jurisprudencia en el nacionalsocialismo se adaptó a la situación política. La seguridad jurídica no existía. Este tribunal se convirtió en un tribunal de venganza contra cualquier forma de resistencia contra el régimen nazi, que se formó durante la Segunda Guerra Mundial tanto en círculos civiles como militares. (Prinz, 2015)
5. Memoria y reconciliación: Se han abierto espacios conmemorativos o bien, se han hecho, placas conmemorativas, monumentos, museos, exposiciones y centros de documentación para la investigación y conmemoración de los crímenes del nazismo y sus víctimas. Por ejemplo, a inicios de los setentas se crearon numerosos Geschichtswerkstätten (clubes de historia local), que comenzaron a realizar investigaciones sobre sus propios pasados nazis locales (Romeike, 2016, pág. 42).

En 1958 se fundó la Organización Acción Servicio de Reconciliación para la Paz (Aktion Sühnezeichen), que intercede como organización de voluntariado a favor de la paz y la reconciliación, siendo el principal ejemplo del compromiso social, porque a través de ella se envió a la gente joven a los países afectados por la II GM, donde trabajaban voluntariamente para solicitar disculpas y paz a las víctimas de la guerra y del nazismo, así como contra la xenofobia y el antisemitismo y desde 1967 la organización presta el servicio voluntario en el lugar conmemorativo de Auschwitz (Romeike, 2016, pág. 42).

En los años noventas hubo una exposición sobre los crímenes de la Wehrmacht, que hasta entonces había sido idealizada como organización que se creía “decente” (Romeike, 2016, pág. 43).

En el 2001 se inauguró el museo judío de Berlín "Das Jüdische Museum Berlin". Posteriormente en esa misma ciudad se inauguraron diversos monumentos como el "Monumento a los judíos de Europa asesinados" en el 2005, el "Monumento a los Homosexuales perseguidos por el nazismo" en el 2008, "el "Monumento a los Sinti y los Roma asesinados" en el 2012 (Romeike, 2016, pág. 43 y 44).

A iniciativas locales, en honor a las personas que murieron durante el Holocausto, se han colocado en algunas calles las Stolpersteine (piedras de tropiezo), que se trata de unos bloques de hormigón 
del tamaño de adoquines en cuya superficie hay una placa de latón incrustada en la que están grabados el nombre, fecha de nacimiento y datos del destino de las personas que fueron persegudas por los nazis y son colocadas en la calle frente al último lugar de residencia, en total, se colocaron 50,000 de estas Stolpersteine en 1300 lugares de Europa y el proyecto se amplió a la instalación de Stolperschwellen (bloques conmemorativos alargados en lugar de cúbicos) en los lugares donde se habían cometido asesinatos masivos (Romeike, 2016, pág. 44).

\section{III.IV. Las Herramientas de Prevención Internacionales después del conflicto}

Posconflicto se estableció el TMI de Núremberg. Asimismo, casi a los tres años posteriores de que la ONU empezará a operar en el $1945^{37}$, el 9 de diciembre de 1948, la Asamblea General de las Naciones Unidas aprobó la Convención para la Prevención y Sanción del Delito de Genocidio (en adelante CPSDG), señalando que el objetivo de la convención es evitarquevolviesen a ocurrir genocidios como los cometidos por los nazis. También, la Asamblea General de la ONU (En adelante AGONU) mediante resolución 60/7 reconoció que durante este conflicto se perpetró el crimen de genocidio, al recordar que la Convención de 1948 se aprobó "para evitar que volvieran a repetirse genocidios como los cometidos por el régimen nazi”, (AGONU, 2005) y; resolvió conducentemente lo siguiente:

1. Decide que las Naciones Unidas designen el 27 de enero Día Internacional de Conmemoración anual en memoria de las víctimas del Holocausto;

37 En 1945, representantes de 50 países se reunieron en San Francisco en la Conferencia de las Naciones Unidas sobre Organización Internacional, para redactar la Carta de las Naciones Unidas. La Carta fue firmada el 26 de junio de 1945 por los representantes de los 50 países. Polonia, que no estuvo representada, la firmó más tarde y se convirtió en uno de los 51 Estados Miembros fundadores. Las Naciones Unidas empezaron a existir oficialmente el 24 de octubre de 1945, después de que la Carta fuera ratificada por China, Francia, la Unión Soviética, el RU, los EUA y la mayoría de los demás signatarios. (ONU)
2. Insta a los Estados Miembros a que elaboren programas educativos que inculquen a las generaciones futuras las enseñanzas del Holocausto con el fin de ayudar a prevenir actos de genocidio en el futuro $y$, en ese contexto, encomia al Grupo de Trabajo para la cooperación internacional en la enseñanza, recordación e investigación del Holocausto;

3. Rechaza toda negación, ya sea parcial o total, del Holocausto como hecho histórico;

4. Encomia a los Estados que han participado activamente en la preservación de los lugares que sivieron de campos de exterminio, campos de concentración, campos de trabajo forzoso y cárceles nazis durante el Holocausto;

5. Condenasinreservastodaslasmanifestaciones de intolerancia religiosa, incitación, acoso o violencia contra personas o comunidades basadas en el origen étnico o las creencias religiosas, dondequiera que tengan lugar;

6. Pide al Secretario General que establezca un programa de divulgación titulado "El Holocausto y las Naciones Unidas" y que adopte medidas para movilizar a la sociedad civil en pro de la recordación del Holocausto y la educación al respecto, con el fin de ayudar a prevenir actos de genocidio en el futuro; que le informe sobre el establecimiento del programa en un plazo de seis meses a contar desde la fecha de aprobación de la presente resolución; y que le informe, en su sexagésimo tercer período de sesiones, sobre la ejecución del programa. (AGONU, 2005)

\section{IV. ¿QUÉ CRÍMENES INTERNACIONALES TIPIFICADOS EN EL ESTATUTO DE ROMA APLICAN AL PRESENTE CONFLICTO? \\ IV.I. Crimen de Lesa Humanidad (CLH)}

De los 24 acusados en el Tribunal de Núremberg, 16 fueron condenados por haber cometido Crimen Contra la Humanidad (En adelante $\mathrm{CCH}$ ) y 2 de 
forma exclusiva ${ }^{38}$. Sin embargo, las definiciones establecidas tanto en el Art. 7 del ER adoptado en 1998 como en el Art. 6 literal a), del Estatuto del TMI de Núremberg de 1945, tienen algunas diferencias:

a. Si bien en ambas normas el sujeto pasivo es una población civil, la diferencia es en el contexto que sean cometidos. El $\mathrm{CCH}$ es dependiente de la guerra, es decir, se debe probar un nexo con un conflicto armado. En el CLH no se requiere ese nexo.

b. En el CLH es indispensable el elemento subjetivo que las conductas sean cometidas como parte de un ataque generalizado o sistemático, es decir, como parte de una línea de conducta de conformidad con la política de un Estado o de una organización de cometer ese ataque o para promover esa política.

c. La conducta de Persecución en el $\mathrm{CCH}$ se limita a motivos raciales, políticos y religiosos, en cambio, en el CLH se extiende a motivos nacionales, étnicos, culturales, de género u otros universalmente reconocidos como inaceptables con arreglo al Derecho Internacional.

d. En el CLH hay mayor número de conductas prohibidas y mejor técnica al tipificarlas, lo que le da mayor claridad a la norma.

Ahora bien, si a estos juicios se hubiese utilizado el tipo penal de Crimen de Lesa Humanidad del ER, también hubiese sido posible probar la comisión del mismo por los siguientes motivos:

1. El CLH no requiere que las conductas sean cometidas durante un Conflicto Armado, por lo

38 1)Hermann Wilhelm Göring; 2) Joachim Von Ribbentrop; 3) Wilhelm Keitel, 4) Ernst Kaltenbrunner; 5) Alfred Rosenberg; 6) Hans Frank; 7) Wilhelm Frick; 8) Julius Streicher: 9) Walter Funk; 10) Baldur Von Schirach; 11) Fritz Sauckel; 12) Alfred Jodl; 13) Arthur Seyss-Inquart; 14) Albert Speer; 15) Constantin Von Neurath, y; 16) Martin Bormann. (De forma exclusiva por $\mathrm{CCH}$ : 8) y 10)) (International Military Tribunal Nuremberg, 1947). que aplican los crímenes de Lesa Humanidad perpetrados antes y durante la II GM.

2. En concomitancia a las conductas, desde que es nombrado Hitler como canciller se empiezan a dar persecuciones por motivos políticos, étnicos, raciales y religiosos; encarcelamientos sin beneficio a juicio y asesinatos; e iniciada la guerra, se empiezan a degenerar las atrocidades y concurren otras conductas como exterminio, esclavitud, tortura, violaciones, esterilizaciones forzadas y desapariciones forzadas.

3. Estas conductas eran en contra de una población civil identificable. Por ejemplo: Los Gitanos, judíos, Testigos de Jehová, homosexuales, polacos católicos, personas con alguna discapacidad e incluso alemanes a fines alguna religión, partido político, por ser parte de la resistencia o prostitutas.

4. Estas conductas eran efectuadas de forma sistemática, porque eran cometidos en diversos tiempos y no de forma casual ${ }^{39}$. Por ejemplo: las víctimas eran identificadas, capturadas, transportadas regularmente en trenes de carga, especialmente conducidos a campos de exterminio donde, si sobrevivían al viaje, la mayoría eran asesinados sistemáticamente en las cámaras de gas, o mediante otros métodos, y;

5. Estas conductas sistemáticas fueron efectuadas de conformidad con la política del Tercer Reich, de cometer esos ataques.

39 "Los patrones de los crímenes, en el sentido de repetición no accidental de una conducta criminal similar de manera regular, son una expresión común de dicha ocurrencia sistemática" Jurisprudencia de la TPIY (IT-95-14/2, 17 de diciembre de 2004) [Traducción no oficial], (Medellín, Arjona Estévez, \& Guevara, 2009, pág. 72) 


\section{IV.II. Genocidio}

Ninguna persona fue acusada por este crimen en los juicios del TMIN ni en los posteriores a este, porque el tipo penal aun no existía, el concepto se acuñó en 1944 y su configuración legal se materializó en 1948 con la aprobación de un instrumento internacional que lo prohíbe. No obstante, el término genocidio, fue utilizado formalmente por primera vez en el TMIN (1945) cuando el fiscal Robert Jackson acusó a los nazis de haber cometido el "crimen de crímenes", pero está no fue retomada por los jueces. (Tinajero \& Guevara, ¿Qué es el genocidio?, 2013 , pág. 19 y 20).

En el supuesto de acusar a los nazis con el tipo penal de genocidio establecido en el artículo 6 del ER, mismo que fue retomado de la CPSDG, art. II; es posible probar la existencia del mismo (existencia que ya fue reconocida por la propia AGONU como ya se mencionó anteriormente por los siguientes motivos:

1. El genocidio puede ser cometido en tiempos de paz o en tiempos de guerra. Por lo que el hecho que haya ocurrido en un contexto de un conflicto armado de carácter internacional no impide para que se configure el tipo penal al presente caso.

2. A diferencia del Crimen de Lesa Humanidad, no es necesario probar que los ataques fueron sistemáticos o generalizados.

3. Las conductas establecidas en el Art. 6 del tipo penal de genocidio fueron cometidas durante el régimen nazi, a excepción del "Traslado por la fuerza de niños del grupo a otro grupo", por el elemento "mens rea”, ya que la intención era eliminar totalmente al grupo que pertenecían (judíos). Por ejemplo:

i. Se realizaron matanzas mediante cámaras de gas y fusilamiento;

ii. Se les produjo lesiones graves a la integridad física o mental de los miembros del grupo a través de tortura, experimentos médicos, aislamiento, entre otros métodos;

iii. Eran sometidos intencionalmente a condiciones de existencia que acarrearon su destrucción física, total o parcial, por ejemplo, los ghettos que eran distritos urbanos comúnmente cerrados en los cuales la población judía vivía en condiciones miserables e insalubres y aunado con el hambre, los inviernos duros, y la falta de servicios públicos resultaron en brotes epidémicos y una alta mortalidad, o como el "campo de las familias gitanas" en Auschwitz que estaba plagado de epidemias como tifus, viruela, y disentería que redujeron severamente la población del campo, y;

iv. Se utilizaron medidas destinadas a impedir nacimientos en el seno del grupo, por ejemplo tanto los gitanos como judíos fueron esterilizados forzosamente.

4. Estas conductas eran en contra de grupos humanos (judíos y "gitanos") los cuales podrían ser agrupados en un grupo religioso 40 o racial ${ }^{41}$ a los judíos, y étnico ${ }^{42}$ o racial a los gitanos. En este orden de ideas, según la jurisprudencia del Tribunal Penal Internacional para Ruanda (TPIR) y del Tribunal Penal Internacional para la Ex-Yugoslavia (TPIY), la determinación del grupo se deberá de realizar con:

40 “...el grupo religioso es aquel que se compone por miembros que practican una misma religión, creencia o rito religiosos" (Tinajero \& Guevara, ¿Qué es el genocidio?, 2013 , pág. 33).

41 "La definición convencional de un grupo racial se basa en características físicas hereditarias, comúnmente identificadas con una región geográfica, sin considerar factores lingüísticos, culturales o religiosos" (Tinajero \& Guevara, ¿Qué es el genocidio?, 2013 , pág. 33).

$42 \mathrm{El}$ derecho internacional determina que grupos étnicos son aquellos colectivos de personas que gozan de vínculos entre sí, los cuales se fundan en razones culturales, de tradición o lingüísticas (Tinajero \& Guevara, ¿Qué es el genocidio?, 2013 , pág. 32). 
1. Bases subjetivas: que el perpetrador perciba a la víctima como perteneciente al grupo que intenta destruir $\mathrm{y}$, paralela pero no forzosamente, que la víctima se identifique con dicho grupo, y; 2.Bases objetivas: con base en las pruebas que proporcionen el contexto histórico, social, cultural y político. (Medellín, Arjona Estévez, \& Guevara, 2009, pág. 66)

En concomitancia al elemento subjetivo, los alemanes determinaban quien era o no judío a través de su ascendencia, linaje o raza: eran judíos todos aquellos que por lo menos tuvieren tres abuelos judíos, independientemente si esa persona se identificaba como judía o pertenecía a la comunidad religiosa judía. Además, las personas que solamente tuviesen uno o dos abuelos judíos eran catalogadas como Mischlinge ( $\mathrm{Pl}$ ) o Mischling (Sing) que al castellano significa hibrido o mestizo.

El que era Mischling era excluido oficialmente del partido nazi y de todas las organizaciones partidarias (por ejemplo, SA, SS, etc.) y a pesar de que eran reclutados por el ejército alemán, no podían alcanzar el rango de oficiales, tampoco podían ser empleados públicos y desarrollar ciertas profesiones (Holocaust Museum Houston). Un Michling podía pasar a ser catalogados como judíos completos por así decirlo, si pertenecían a la comunidad religiosas o si estaban casados con un judío. (Museo Memoria y Tolerancia, 2013, pág. 6).

En conclusión el elemento racial hereditario era el elemento contundente para determinar la pertenencia al grupo sin tomar en cuenta factores nacionales, culturales y solamente por vía de excepción religiosos.

En cuanto al elemento objetivo, el contexto del conflicto, radica en que los alemanes lo veían como una lucha de índole racial, ellos tenían la creencia de que los judíos eran una raza cuyo objetivo era dominar al mundo y, por eso, los consideraban un obstáculo para el dominio ario (Holocaust Museum Houston). Creían que toda la historia se resumía en una lucha entre razas que debían culminar en el triunfo de la raza aria, ante sus ojos, el origen racial de los judíos los convertía en delincuentes habituales cuya rehabilitación resultaba imposible y que, debido a ello, eran irremediablemente corruptos e inferiores (Holocaust Museum Houston).

Si bien es cierto que también otro factor que contribuyó al odio hacia los judíos fue la tradición del antisemitismo cristiano que propagaba un estereotipo negativo del judío como asesino de Cristo, enviado del diablo, o hechicero (Holocaust Museum Houston), la mayoría fue en relación al factor racial al considerarlos con una raza "infrahumana".

Asimismo, las pruebas orientan que fue una persecución racial lo que es visible en las acciones efectuadas durante el conflicto entre las cuales en las leyes promulgadas, propaganda, ideologías del partido nazi y otras organizaciones denotan el odio racial. Por lo que podría concluir que las conductas establecidas en el art. 6 del ER que se dieron durante el conflicto fueron en contra de un grupo racial en relación a los judíos y a prima facie me atrevería colocar a los gitanos.

5. Las conductas en perjuicio de los judíos y gitanos fueron perpetrados con la intención de destruirlos de forma total y parcial respectivamente; en el caso judío la intención fue total en donde es más visible tras la ejecución de la "solución final". En cuanto a los gitanos fue parcial: los historiadores calculan que los alemanes y sus aliados mataron entre 25 y 50 por ciento de los roma gitanos europeos. ${ }^{43}$

\section{IV.III. Crimen de Guerra (CG)}

El TMIN, condenó a 16 personas por haber cometido Crímenes de guerra y violaciones de las 43 "El canciller alemán Helmut Kohl reconoció el genocidio nazi contra los roma en 1982. Para ese momento, la mayoría de los roma que hubieran tenido derecho a la restitución bajo la ley alemana ya habían muerto". (United States Holocaust Memorial Museum) 
Convenciones de La Haya y Ginebra, ninguno de forma exclusiva ${ }^{44}$. La definición establecida en el Art. 6, literal b) del Estatuto del TMIN se diferencia del establecido en el art. 8 del ER en lo siguiente:

1. En el ER se especifican un mayor número de conductas a diferencia del Estatuto del TMIN que se mencionan algunas de forma específica y general.

2. En el ER se reconocen los crímenes de guerra cometidos en conflictos armados no internacionales.

Si aplicamos la definición del ER de Crimen de Guerra en este conflicto no cambiaría el hecho de que se hubiese condenado por este crimen por los siguientes motivos:

1. Se podrían conocer las conductas ocurridas dentro de la II GM, es decir, del 1 de septiembre de 1939 fecha de la invasión alemana a Polonia al 8 de mayo de 1945 fecha en la que los Aliados de la II GM aceptaron la rendición presentada por el jefe de Estado Mayor del Alto Mando de las Fuerzas Armadas alemanas, el general Alfred Jodl. Esto debido al elemento contextual, porque deben ocurrir dentro un conflicto armado internacional o no internacional. Este caso fue de carácter internacional atendiendo lo establecido en el artículo 2 común a los Convenios de Ginebra de $1949^{45}$ y a la jurisprudencia del TPIY, en

44 1)Hermann Wilhelm Göring; 2) Joachim Von Ribbentrop; 3) Wilhelm Keitel, 4) Ernst Kaltenbrunner; 5) Alfred Rosenberg; 6) Hans Frank; 7) Wilhelm Frick; 8) Karl Dönitz: 9) Walter Funk; 10) Erich Raeder; 11) Fritz Sauckel; 12) Alfred Jodl; 13) Arthur SeyssInquart; 14) Albert Speer; 15) Constantin Von Neurath, y; 16) Martin Bormann. ( International Military Tribunal Nuremberg, 1947)

45 "Aparte de las disposiciones que deben entrar en vigor ya en tiempo de paz, el presente Convenio se aplicará en caso de guerra declarada o de cualquier otro conflicto armado que surja entre dos o varias Altas Partes Contratantes, aunque una de ellas no haya reconocido el estado de guerra. El Convenio se aplicará también en todos los casos de ocupación total o parcial del territorio de una Alta Parte Contratante, aunque tal ocupación no encuentre resistencia militar". el caso de Tadic, en el que se propuso la definición general de CAl: "existe conflicto armado cuando se recurre a la fuerza armada entre Estados" (Comité Internacional de la Cruz Roja, 2008).

2. Las conductas que se produjeron fueron en perjuicio de personas protegidas por el Derecho Internacional Humanitario (CG 1949), por ejemplo, población civil ${ }^{46}$ en terrenos ocupados y extranjeros del Estado beligerante (grupos específicos de civiles: refugiados, detenidos, internados, personal religioso civil, mujeres y niños), prisioneros de guerra soviéticos y de otras nacionalidades, militares heridos y enfermos en campo de batalla y en el mar; e incluso sobre bienes protegidos (civiles y culturales), y;

3. Varios de los hechos que se produjeron durante la II Guerra Mundial cuadran en las conductas del tipo penal de Crimen de Guerra, por ejemplo:

I. Matanza de la población civil y de prisioneros perpetrada por las fuerzas alemanas ${ }^{47}$;

II. Violaciones masivas de mujeres por parte de tropas soviéticas y estadounidenses, asimismo las fuerzas de la Wehrmacht cometieron violaciones contra mujeres y adolescentes judías durante la invasión de Polonia, e incluso estos, dirigían burdeles donde las mujeres eran forzadas a prostituirse ${ }^{48}$;

46 Los Convenios de Ginebra de 1949 ampliaron la protección específica a los civiles, quienes habían sufrido enormemente durante la Segunda Guerra Mundial, y con frecuencia porque fueron elegidos deliberadamente como blanco de los ataques. La protección de la población civil, en especial contra los efectos de las hostilidades, está contemplada también en los Protocolos adicionales de 1977. (Comité Internacional de la Cruz Roja, 2010) 47 “...i) El homicidio intencional...”. (Estatuto de Roma, artículo 8, Párrafo 2, letra a), inciso i))

48 : “...xxii) Cometer actos de violación, esclavitud sexual, prostitución forzada, embarazo forzado, definido en el apartado f) del párrafo 2 del artículo 7, esterilización forzada y cualquier otra 
III. La destrucción intencionada de importantes iglesias medievales en Novgorod y de monasterios de la región de Moscú como el monasterio de Nueva Jerusalén y de los palacios imperiales alrededor de San Petersburgo. También, durante la invasión de la Alemania nazi a Polonia, además de perder algo más del $16 \%$ de su población, la política deliberada y sistemática de aniquilación nazi incluía borrar también su legado cultural, su huella arquitectónica dejando por consecuencia de ello el $85 \%$ de la capital convertida en escombros y en el conjunto del país el $43 \%$ de los monumentos resultaron destruidos, entre ellos, el Castillo Real de Varsovia, la Archicatedral de San Juan de finales del siglo XIV, la Iglesia de Santa Ana de mediados del siglo XV y el Palacio Staszic de comienzos del XIX, fueron en total 782 monumentos polacos que desaparecieron ${ }^{49}$;

IV. Torturas, tratos inhumanos e incluso experimentos biológicos a prisioneros y rehenes en los campos de concentración ${ }^{50}$;

V. Deportaciones masivas ${ }^{51}$ a campos de concentración y de trabajo forzado organizados en Europa por Alemania que se convertirían en campos de exterminio; entre

forma de violencia sexual que también constituya una infracción grave de los Convenios de Ginebra..." (Estatuto de Roma, artículo 8, Párrafo 2, letra b), inciso xxii))

49 “... ix) Dirigir intencionalmente ataques contra edificios dedicados a la religión, la educación, las artes, las ciencias o la beneficencia, los monumentos históricos, los hospitales y los lugares en que se agrupa a enfermos y heridos, siempre que no sean objetivos militares" (Estatuto de Roma, artículo 8, Párrafo 2, letra a), inciso viii) y artículo 8 , Párrafo 2 , letra b), inciso ix))

50 ii) La tortura o los tratos inhumanos, incluidos los experimentos biológicos; “...x) Someter a personas que estén en poder de una parte adversa a mutilaciones físicas o a experimentos médicos o científicos de cualquier tipo que no estén justificados en razón de un tratamiento médico, dental u hospitalario, ni se lleven a cabo en su interés, y que causen la muerte o pongan gravemente en peligro su salud;.." (Estatuto de Roma, artículo 8, Párrafo 2, letra a), inciso ii) y artículo 8 , Párrafo 2 , letra b), inciso $\mathrm{x}$ ))

51 vii) La deportación o el traslado ilegal o el confinamiento ilegal..." (Estatuto de Roma, artículo 8, Párrafo 2, letra a), inciso vii)) otras conductas prohibidas que cuadran en el tipo penal.

\section{REFLEXIONES FINALES}

Identificadas en el presente caso las diez etapas por las que atraviesan todos los genocidios de Gregory $\mathrm{H}$. Stanton, es notoriamente visible que el mismo no fue fruto de la espontaneidad ni imprevisible sino más bien fue evolucionando en varias etapas predecibles, aunque no inexorables. Por ello se podría decir que durante el desarrollo de estas etapas era posible tomar medidas para prevenirlas, como el mismo Stanton menciona y propone tales como el desarrollo de instituciones universalistas que trasciendan divisiones étnicas o raciales, que promuevan activamente la tolerancia y la comprensión, y que promuevan clasificaciones que trascienden las divisiones; prevención contra la discriminación; restricciones de viaje, embargo de armas, congelamiento de finanzas extranjeras, sanciones diplomáticas; establecimiento de Comisiones de Investigación, entre otras medidas. Sin embargo, en el presente caso las medidas adoptadas tanto nacionales como internacionales no fueron efectivas para evitar la cristalización del mismo.

Con respecto a lo antes señalado, la prevención, debe entenderse en lato sensu, tanto antes, durante y una vez ocurrida una atrocidad. La importancia de la prevención es que contribuye a la paz y estabilidad nacional; preservar la vida humana; sirven también para la paz y estabilidad regional e internacional; la prevención es mucho menos costosa que intervenir para detener crímenes internacionales o para lidiar con sus consecuencias; con la adopción de medidas de prevención y el ejercicio de su responsabilidad de proteger a su población, los Estados refuerzan su soberanía y reducen la necesidad de medios de respuesta más intrusivos por otros Estados o actores internacionales. Las herramientas de prevención de atrocidades de violencia generalizada las podríamos clasificar en nacionales e internacionales. 
Las Herramientas de prevención nacionales pueden ser:

1. Medidas económicas: por ejemplo reducción de la pobreza y/o desigualdad, apertura comercial, desarrollo económico;

2. Medidas de gobernanza: entendiéndose por estas, las leyes y estructuras del Estado, como leyes que tipifiquen los crímenes, leyes que contemplen derechos humanos, instituciones, democracia, independencia judicial, erradicar la corrupción, políticas públicas;

3. Medidas de seguridad: todas aquellas que tiendan a preservar el Estado de Derecho: erradicando la impunidad, sistema de seguridad, desarme, control de armas;

4. Medidas sociales como la protección de Derechos Humanos, libertad de expresión, diálogo intercultural, sociedad civil, educación, en otras palabras, que sea una sociedad que fomente la convivencia entre diversos grupos, $\mathrm{y}$;

\section{La Justicia Transicional.}

Por otro extremo, cuando el Estado no puede evitar una atrocidad, entran las Herramientas de prevención internacionales, entre las cuales están:

1. Los Mecanismos de Alerta Temprana ${ }^{52}$ que

52 Un Sistema de Alerta y Respuesta Temprana (SART) es una herramienta cuyo objetivo primordial es evitar escaladas de violencia que pongan en riesgo la integridad de las personas y la gobernabilidad democrática. Los SART son mecanismos de prevención y atención de conflictos que se enfocan en la recolección sistemática (cuantitativa o cualitativa), procesamiento y análisis de información de situaciones de conflicto cuyo propósito es alertar a los decisores políticos para tomar medidas o acciones que eviten el surgimiento o escalada de un conflicto. Estos sistemas están orientados a: - Identificar las causas de un conflicto • Predecir su estallido • Mitigar su impacto Estos sistemas son variados pero es posible identificar, al menos, dos tipos generales: a. Los Sistemas de Alerta Temprana (SAT) cuya tarea se circunscribe a informar y alertar sobre la ocurrencia de eventos que representen riesgos a las personas y la estabilidad democrática de un determinado país o región. Su objetivo final es prevenir desenlaces violentos, pueden ser de la ONU, OEA, Unión Europea, Unión Africana, Conferencia de Grandes Lagos u Organizaciones No Gubernamentales;

2. Medidas Diplomáticas como el establecimiento de Comisiones de Investigación, Misiones de Expertos Independientes, Buenos Oficios y Grupos de Amigos;

3. Brindar refugio a las víctimas del conflicto;

4. Sanciones del CSONU o de otros Estados: por ejemplo, restricciones de viaje, embargo de comercio o armas, congelamiento de activos, sanciones diplomáticas;

5. Despliegue de Operaciones de Paz;

6. Medidas Penales: como la instalación de tribunales penales internacionales o híbridos;

7. Incentivos: que pueden ser económicos, comerciales y políticos, y;

8. La responsabilidad de Proteger: es un principio de connotación política y no jurídica, porque no crea obligaciones jurídicas a los Estados puesto que se trata de una declaración per se y no de un tratado internacional. Surge en respuesta a las atrocidades de violencia generalizada ocurridas en el siglo XX, como las acaecidas en Camboya, Rwanda, Srebrenica, y por supuesto, en el Holocausto (AGONU, 2009). Este principio extiende al concepto de Soberanía, puesto que "ya no significa únicamente protección de los Estados frente a injerencias extranjeras, sino que constituye una carga de responsabilidad que obliga a los Estados a responder del bienestar de su población" (ONU). La Responsabilidad de Proteger consta de tres pilares, mismos que están estipulados en el Documento Final de la Cumbre Mundial 2005 y enunciados en el informe del 2009, del Ex Secretario General de la ONU, Ban Ki-moon, titulado "Hacer efectiva la responsabilidad de proteger", siendo los siguientes:

1. Responsabilidad del Estado ${ }^{53}$.

no solamente anticiparlos. b. Los Sistemas de Alerta y Respuesta Temprana (SART), consideran además de lo anterior, un conjunto de recomendaciones sobre cómo proceder en estos casos. (OEA, PUND, 2016, pág. 11)

53 "Cada Estado es responsable de proteger a su población del genocidio, los crímenes de guerra, la depuración étnica y los 
2. Responsabilidad de asistencia de la comunidad internacional ${ }^{54}$.

3. Responsabilidad de la comunidad internacional de utilizar los medios diplomáticos, humanitarios y otros medios apropiados si es evidente que un Estado no protege a su población $^{55}$.

Para finalizar, es importante mencionar que la Doctrina de la Responsabilidad de Proteger es una reafirmación política de obligaciones jurídicas que ya existen en instrumentos internacionales de carácter vinculante, por ejemplo, en el artículo 1 de la Convención para la prevención y la sanción del delito de genocidio de 1948 conducentemente estipula: "Las Partes contratantes confirman que el genocidio, ya sea cometido en tiempo de paz o en tiempo de guerra, es un delito de derecho internacional que ellas se comprometen a prevenir y a sancionar", otro ejemplo, en el artículo 1 común de los convenios de ginebra de 1949 que reza: "Las Altas Partes Contratantes se comprometen a respetar y a hacer respetar el presente Convenio en todas las circunstancias"; entre otros, en consecuencia, este principio viene hacer un llamado sobre la importancia de la prevención, protección y colaboración entre los países para ese objetivo y evitar de esta manera atrocidades masivas, en específico, crímenes como el genocidio, los crímenes de guerra, la depuración étnica y los crímenes de lesa humanidad, mismos que por desgracia se cristalizaron durante el Holocausto y en atrocidades masivas posteriores a esta.

crímenes de lesa humanidad. Esa responsabilidad conlleva la prevención de dichos crímenes, incluida la incitación a su comisión, mediante la adopción de las medidas apropiadas y necesarias" (AGONU, 2005, párr. 138).

54 "La comunidad internacional debe, según proceda, alentar y ayudar a los Estados a ejercer esa responsabilidad y ayudar a las Naciones Unidas a establecer una capacidad de alerta temprana" (AGONU, 2005, párr. 138).

55 "La comunidad internacional, por medio de las Naciones Unidas, tiene también la responsabilidad de utilizar los medios diplomáticos, humanitarios y otros medios pacíficos apropiados, de conformidad con los Capítulos VI y VIII de la Carta, para ayudar a proteger a las poblaciones del genocidio, los crímenes de guerra, la depuración étnica y los crímenes de lesa humanidad" (AGONU, 2005, párr. 139).

\section{BIBLIOHEMEROGRAFÍA}

ACNUR. (15 y 16 de Octubre de 2013). Reunión de expertos Interpretación de la definición ampliada de refugiado contenida en la Declaración de Cartagena sobre Refugiados de 1984. Resumen de las conclusiones sobre la interpretación de la definición ampliada de refugiado de la Declaración de Cartagena de 1984 . Montevideo, Uruguay. Obtenido de http://www.acnur.org/fileadmin/ Documentos/BDL/2014/9651.pdf

AGONU. (24 de Octubre de 2005). 60/1. Documento Final de la Cumbre Mundial 2005 . Recuperado el 14 de Octubre de 2018, de Sitio Web de la ONU: $\quad$ https://www2.ohchr.org/spanish/bodies/ hrcouncil/docs/gaA.RES.60.1_Sp.pdf

AGONU. (12 de Enero de 2009). Hacer efectiva la responsabilidad de proteger, Informe del Secretario General. Recuperado el 19 de Agosto de 2017, de Sitio Web ONU: http://www.un.org/ es/comun/docs/?symbol=A/63/677

AGONU. (1 de Noviembre de 2005). Resolución aprobada por la Asamblea General, 60/7. Recordación del Holocausto. Recuperado el 2017 de Mayo de 11, de Sitio web de la Organización de las Naciones Unidas, ONU: http://www.un.org/ es/holocaustremembrance/res607.shtml

Ambos, K., \& Meyer, N. (2009). Justicia de Transición: Informes de América Latina, Alemania, Italia y España. (K. Ambos, E. Malarino, \& G. Elsner, Edits.) Montevideo: Konrad-Adenauer.

Antisemitismus.net. (s.f.). Recuperado el 2 de mayo de 2017, de Sitio web de Antisemitismus.net: http://www.antisemitismus.net/shoah/holocaust. htm

Centro Internacional para la Justicia Transicional. (s.f.). ¿Qué es la Justicia Trancisional? Recuperado el 28 de Julio de 2017, de Sitio Web de Centro Internacional para la Justicia Transicional: https:// www.ictj.org/es/que-es-la-justicia-transicional 
Centro Internacional para la Justicia Transicional. (s.f.). Verdad y Memoria . Recuperado el 17 de Agosto de 2017, de Centro Internacional para la Justicia Transicional: https://www.ictj.org/es/ our-work/transitional-justice-issues/verdad-ymemoria

Comisión Andina de Juristas, CAJ. (2004). La Corte Penal Internacional y los países andinos (Segunda ed.). Lima.

Comisión de Amnistía del Ministerio de Justicia de Brasil, ICTJ. (2011). Justicia Transicional, Manual para América Latina. (F. Reátegui, Ed.)

Comité Internacional de la Cruz Roja. (29 de Octubre de 2010). Recuperado el 11 de Mayo de 2017, de Sitio web del CICR: https://www.icrc. org/spa/war-and-law/protected-persons/overviewprotected-persons.htm

Comité Internacional de la Cruz Roja. (Marzo de 2008). Cuál es la definición de "conflicto armado" según el derecho internacional humanitario. Recuperado el 11 de Mayo de 2017, de Sitio Web de International Committee of The Red Cross: https://www.icrc.org/spa/assets/files/other/ opinion-paper-armed-conflict-es.pdf

Gregory H, S. (2013). Recuperado el 8 de Junio de 2017, de Sitio web de Genocide watch: http:// www.genocidewatch.org/images/Ten_Stages_of_ Genocide_by_Gregory_Stanton.pdf

Guevara, J., \& del Maso, T. (2005). La Corte Penal Internacional: Una visión Iberoamericana. México: Porrúa.

Historia virtual del Holocausto. (s.f.). Recuperado el 3 de Mayo de 2017, de Sitio web de Historia Virtual del Holocausto: http://www.elholocausto. net/parte01/0120.htm

Hitler, A. (2003). Mi Lucha. Chile: Jusego.
Holocaust Museum Houston. (s.f.). Preguntas que se hacen frecuentemente: Museo del Holocausto de Houston, Houston . Houston, Estados Unidos de América. Recuperado el 6 de Mayo de 2017, de file:///D:/IBERO\%2OMAESTRIA\%20DE\%20 DERECHOS\%2OHUMANOS/DIH\%20y\%20DPI/ FAQ\%20Holocaust\%20SP\%20EI\%20Museo\%20 del\%20Holocausto\%20de\%20Houston.pdf

International Military Tribunal Nuremberg. (1947). Recuperado el 20 de Mayo de 2018, de Trial of The Major War Criminals Before The International Military Tribunal Nuremberg: https://www.loc.gov/ rr/frd/Military_Law/pdf/NT_Vol-I.pdf

Medellín, X., Arjona Estévez, J. C., \& Guevara, J. A. (2009). Manual básico sobre la Corte Penal Internacional . México: Fundación Konrad Adenauer.

Museo Memoria y Tolerancia. (2013). Guía para Estudiantes: Cédulas Museo Memoria y Tolerancia. México: MMyT.

Museo Memoria y Tolerancia, Ciudad de México. (2011.). Museo Memoria y Tolerancia. México, D.F: Museo Memoria y Tolerancia.

OEA, PUND. (Marzo de 2016). Programa de las Naciones Unidas para el Desarrollo . Recuperado el 19 de Agosto de 2017, de http://www. latinamerica.undp.org/content/rblac/es/home/ library/democratic_governance/guia-practicapara-el-diseno-de-sistemas-de-alerta-yrespuesta-t.html

ONU. (1998). Estatuto de Roma de la Corte Penal Internacional . Roma: ONU.

ONU. (s.f.). Historia de las Naciones Unidas. Recuperado el 9 de Mayo de 2017, de Sitio Web de la Organización de las Naciones Unidas: http:// www.un.org/es/sections/history/history-unitednations/index.html

ONU. (s.f.). ONU. Recuperado el 19 de Agosto de 
2017, de http://www.un.org/es/preventgenocide/ adviser/responsibility.shtml

Prinz, C. (15 de Julio de 2015). Deutsches Historisches Museum, Berlin. Recuperado el 20 de Mayo de 2018, de LEMO: https://www. $\mathrm{dhm}$.de/lemo/kapitel/ns-regime/innenpolitik/ volksgerichtshof.html

Real Academia Española. (2017). Real Academia Española. Recuperado el 14 de Octubre de 2018, de http://dle.rae.es/?id=TUlaoAR

Romeike, S. (2016). La justicia transicional en Alemania después de 1945 y después de 1989. Recuperado el 12 de Junio de 2017, de Sitio web de Nuremberg Academy: https://www. nurembergacademy.org/fileadmin/media/pdf/ publications/Justicia_transicional_en_Alemania. pdf

Sales, F. (17 de Febrero de 2000). El presidente de Alemania pide perdón en Israel por el holocausto. Recuperado el 9 de Mayo de 2017, de Sitio web de El País: http://elpais.com/diario/2000/02/17/ internacional/950742020_850215.html

Tinajero, S., \& Guevara, J. A. (2013 ). ¿Qué es el genocidio? México : MMyT, CDHDF,INACIPE.

United States Holoaust Memorial Museum. (s.f.). Einsatzgruppen. Recuperado el 4 de Mayo de 2017, de Sitio web de United States Holoaust Memorial Museum: https://www.ushmm.org/wlc/ en/article.php?Moduleld $=10005130$

United States Holoaust Museum. (s.f.). Los juicios posteriores de Núremberg. Recuperado el 6 de Mayo de 2017, de Sitio web de United States Holoaust Museum: https://www.ushmm.org/wlc/ es/article.php?Moduleld =10008036

United States Holocaust Memorial Museum. (s.f.). ¿Cómo se definieron los crímenes? Recuperado el 6 de Mayo de 2017, de Sitio web de United States Holocaust Memorial
Museum: https://www.ushmm.org/wlc/es/article. php?Moduleld $=10008019$

United States Holocaust Memorial Museum. (s.f.). Conferenia de Wannsee y "la Solución Final". Recuperado el 3 de Mayo de 2017, de Sitio web de United States Holocaust Memorial Museum: https://www.ushmm.org/wlc/es/article. php?Moduleld $=10007781$

United States Holocaust Memorial Museum. (s.f.). Cronología de la negación del Holocausto. Recuperado el 4 de Mayo de 2017, de Sitio web de United States Holocaust Memorial Museum: https://www.ushmm.org/wlc/es/article. php?Moduleld $=10008085$

United States Holocaust Memorial Museum. (s.f.). El Genocidio de los roma europeos (gitanos), 1939-1945. Recuperado el 11 de Mayo de 2017, de Sitio web de United States Holocaust Memorial Museum: https://www.ushmm.org/wlc/ es/article.php?Moduleld =10006054

United States Holocaust Memorial Museum. (s.f.). Gestapo. Recuperado el 3 de Mayo de 2017, de Sitio web de United States Holocaust Memorial Museum: https://www.ushmm.org/wlc/en/article. php?Moduleld $=10008218$

United States Holocaust Memorial Museum. (s.f.). Hitler llega al poder. Recuperado el 2 de Mayo de 2017, de Sitio web de United States Holocaust Memorial Museum: https://www.ushmm.org/ outreach/es/article. php? Moduleld $=10007671$

United States Holocaust Memorial Museum. (s.f.). Kristallnacht. Recuperado el 13 de Mayo de 2017, de Sitio web de United States Holocaust Memorial Museum: https://www.ushmm.org/wlc/ es/article.php?Moduleld=10007096

United States Holocaust Memorial Museum. (s.f.). La población judía de Europa en 1933. Recuperado el 6 de Junio de 2017, de sitio web de United States Holocaust Memorial 
Museum: https://www.ushmm.org/wlc/es/article. php?Moduleld =10006026

United States Holocaust Memorial Museum. (s.f.). La vida de los judíos en Europa antes del Holocausto. Recuperado el 2 de mayo de 2017 , de Sitio web de United States Holocaust Memorial Museum: https://www.ushmm.org/outreach/es/ article.php?Moduleld=10007689.

United States Holocaust Memorial Museum. (s.f.). Las leyes raciales de Núremberg. Recuperado el 2 de Mayo de 2017, de Sitio web de United States Holocaust Memorial Museum: https://www.ushmm.org/outreach/es/article. php?Moduleld=10007695

United States Holocaust Memorial Museum. (s.f.). Los judíos en la Alemania de la preguerra. Recuperado el 3 de Mayo de 2017, de Sitio web de United States Holocaust Memorial Museum: https://www.ushmm.org/outreach/es/article. php?Moduleld =10007687

United States Holocaust Memorial Museum. (s.f.). Los Juicios de Núremberg. Recuperado el 6 de Mayo de 2017, de Sitio web de United States Holocaust Memorial Museum: https://www.ushmm.org/ outreach/es/article.php?Moduleld=10007722

United States Holocaust Memorial Museum. (s.f.). SA/Sturmabteilung. Recuperado el 13 de Mayo de 2017, de Sitio web de United States Holocaust Memorial Museum: https://collections.ushmm. org/search/catalog/irn518903

United States Holocaust Memorial Museum. (s.f.). The SS. Recuperado el 2017 de Mayo de 2017, de Sitio web de United States Holocaust Memorial Museum: https://www.ushmm.org/wlc/en/article. php?Moduleld =10007400

United States Holocaust Mmeorial Museum. (s.f.). Los Campos de Exterminio. Recuperado el 3 de Mayo de 2017, de Sitio web de United States Holocaust Mmeorial Museum: https://www.ushmm.org/wlc/
es/article.php?Moduleld=10005768

Universitat de les illes Belears. (s.f.). Recuperado el 6 de Mayo de 2017, de Sitio web de Universitat de les illes Belears: http://fci.uib.es/Servicios/ libros/veracruz/Fraschina/1.-Los-TribunalesMilitares-Internacionales..cid210831

Villa, H. V. (26 de Octubre de 2007). Conferencia magistral impartida en la Cátedra Latinoamericana “Julio Cortázar" de la Universidad de Guadalajara, México. Recuperado el 17 de Agosto de 2017, de http://escolapau.uab.es/img/programas/derecho/ justicia/seminariojt/tex03.pdf 